\title{
Successes and failures in producing attentional object-based cueing effects
}

\author{
Irene Reppa • William C. Schmidt • E. Charles Leek
}

Published online: 4 November 2011

(C) Psychonomic Society, Inc. 2011

\begin{abstract}
Over 30 years of research using Posner's spatial cueing paradigm has shown that selective attention operates on representations of spatial locations, leading to space-based theories of attention. Manipulations of stimuli and methods have shown this paradigm to be sensitive to several types of object-based representations - providing evidence for theories incorporating object-based attentional selection. This paper critically evaluates the evidence demanding object-based explanations that go beyond positing spatial representations alone, with an emphasis on identifying and interpreting successes and failures in obtaining object-based cueing effects. This overview of current evidence is used to generate hypotheses regarding critical factors in the emergence and influence of object representations-their generation, strength, and maintenance - in the modulation of objectbased facilitatory and inhibitory cueing effects.
\end{abstract}

Keywords Selective attention - Object-based - Spacebased $\cdot$ Facilitation $\cdot$ IOR

We gratefully acknowledge Janice J. Snyder for inspiring a comprehensive table-based approach to integrating research findings. This paper benefited greatly from the review process and we thank the editor and the reviewers for their contribution.

\footnotetext{
I. Reppa $(\square)$

Wales Institute for Cognitive Neuroscience, Department of Psychology, Swansea University,

Swansea SA2 8PP Wales, UK

e-mail: i.reppa@swansea.ac.uk

W. C. Schmidt

SR Research,

Mississauga, Canada

E. C. Leek

Wales Institute for Cognitive Neuroscience, School of Psychology, Bangor University,

Bangor, Wales, UK
}

Many different experimental paradigms have been used to investigate the role of objects in visual selection (see Cave \& Bichot, 1999, and Scholl, 2001, for reviews). Through converging operations, strong evidence has emerged revealing that object-based representations can mediate attentional selection. Examples of such paradigms include studies of the attentional blink within and between objects (e.g., Conci \& Müller, 2009), divided attention within and between objects (e.g., Atchley \& Kramer, 2001; Awh, Dhaliwal, Christensen, \& Matsukura, 2001; Duncan, 1984; Vecera, Behrmann, \& Filapek, 2001; Vecera, Behrmann, \& McGoldrick, 2000), response competition (e.g., Baylis \& Driver, 1992; Kramer \& Jacobson, 1991; Richard, Lee, \& Vecera, 2008), multiple-object tracking (e.g., Scholl, Pylyshyn, \& Feldman, 2001), negative priming (e.g., Mari-Beffa, Houghton, Estevez, \& Fuentes, 2000; Tipper, Brehaut, \& Driver, 1990), visual marking (e.g., Watson \& Humphreys, 1998), visual search in multiple-object displays (e.g., Enns \& Rensink, 1990; Goldsmith, 1998; Grossberg, Mingolla, \& Ross, 1994; Rensink \& Enns, 1995; Treisman, 1982; Wolfe \& Bennett, 1997), and spatial cueing (e.g., Egly, Driver, \& Rafal, 1994; Tipper, Driver, \& Weaver, 1991). In each of these literatures, positing that attention operates on representations of objects has provided more thorough and satisfying explanations of data than would simply assuming that attention operates on spatial representations alone. The present review concentrates on evidence for claims of object-based selection from studies using the spatial cueing paradigm.

\section{Why spatial cueing?}

A key motivation for focusing on spatial cueing is that claims have emerged that object-based spatial cueing 
effects are fragile: smaller in magnitude, uneasily predicted, and not observed under as wide a range of experimental manipulations as space-based effects (for facilitatory effects, see, e.g., Kwak \& Egeth, 1992; Robertson \& Kim, 1999; for inhibitory effects, List \& Robertson, 2007; McAuliffe, Pratt, \& O’Donnell, 2001; Pratt \& McAuliffe, 1999; Schendel, Robertson, \& Treisman, 2001).

Although all candidate representations of attention encode space and produce space-based effects, it is the contention of the present review that an assumption that attention operates on representations of objects and their parts is required in order to fully explain evidence from the spatial cueing paradigm. Surveying the large number of data points available from spatial cueing experiments may reveal some important factors that contribute to the observation and magnitude of object-based effects.

Apart from empirically examining the robustness of object-based effects, there are at least three other reasons to focus on the spatial cueing paradigm when looking for evidence in support of object-based representations. First, spatial cueing is a seemingly simple paradigm that ought to yield tractable insight into the properties of attentional selection before considering behaviour in more complex paradigms. Second, despite the conceptual simplicity of spatial cueing, many of its different aspects and parameters have been investigated, yielding a large data set, from one of the historically earliest paradigms used to probe selective attention. Importantly, these include manipulations of perceptual factors that may influence the type of representations mediating selection. Historically, the presence of converging evidence produced by a large number of studies generated from different laboratories means that researchers can have increased confidence that they are not being misled by Type I or Type II errors. Third, as will be clear later, the spatial cueing task allows for the experimental examination of facilitatory and inhibitory mechanisms of attention, supplying foundational evidence that facilitatory and inhibitory processes can operate in parallel and on different representations produced by the same visual display.

The aim of this review is to recount and evaluate reported object-based spatial cueing effects in order to understand successes and failures in obtaining them, and consequently to make predictions about their likely occurrence and magnitude in future investigations. In doing so, we critically evaluate object-based effects and the necessity of explaining spatial cueing effects in terms of attention operating on representations of objects, or whether positing more primary, spacebased representations is sufficient to explain the data.

After describing the spatial cueing paradigm and its resulting facilitatory and inhibitory effects, we review evidence pertaining to the influence of spatial factors on the presence and magnitude of such effects. Evidence for the role of the generation and maintenance of object-based representations in the modulation of facilitatory and inhibitory cueing effects will then be reviewed from spatial cueing studies using moving object stimuli, followed by a review of studies using static object stimuli. Potential factors involved in the emergence and maintenance of object representations during spatial cueing tasks are discussed in each section. Finally, alternative space-based accounts of the data are evaluated in light of the current evidence, followed by a summary and conclusions.

\section{Covert orienting and the spatial cueing paradigm}

Imagine that you are driving along a country road. A bird swoops through the air above your oncoming path. Your visual system may have processed its presence and you may have disregarded it as a threat without having moved your eyes, or more importantly, without having begun steering towards the bird's location. Such covert orienting of attention allows us to filter sensory information in the absence of, or prior to, any overt realignment of sensory receptors towards the stimulus. Given the presence of limitations in processing capabilities (sensory and motor), covert orienting is fundamental to the selective and efficient processing of sensory information, and it plays a key role in our ability to monitor and interact with the environment and its physical contents.

The spatial cueing paradigm has been one of the primary methods used to study covert attentional processing for the past 30 years. A typical spatial cueing task involves the simultaneous presentation of two placeholders (e.g., squares) at equal distances to the left and right of a central fixation point; see Fig. 1a. One placeholder is briefly highlighted by a luminance increment, which is referred to as a "peripheral cue" and is presumed to orient attention to that placeholder or cued location. The target is presented a short time later either within the peripherally cued placeholder (the cued or valid location condition) or within the opposite placeholder (the uncued or invalid location condition). While spatial cueing often involves a simple target detection response, variants include target discrimination and target identification - responding based on a prespecified feature or combination of features (e.g., Brawn \& Snowden, 2000; Maylor, 1985; Tanaka \& Shimojo, 1996).

Spatial cueing typically produces significant benefits or costs for subsequent target processing at the cued location, depending on the cue-target onset asynchrony (e.g., Posner, 1980; Posner \& Cohen, 1984) - see Fig. 1b. At 50- to 300-ms cue-target onset asynchronies (also called stimulus onset asynchronies, or SOAs), target detection is speeded or facilitated by cueing: That is, response times (RTs) are faster to targets appearing at cued (valid) as compared to uncued (invalid) locations. In contrast, at cue-target 
Fig. 1 a Typical spatial cueing task (Posner cueing task) and $\mathbf{b}$ typical pattern of RT results depending on cue-target stimulus onset asynchrony (SOA). Adapted from "Inhibition of Return” by R. M. Klein, 2000, Trends in Cognitive Sciences, 4, pp. 138-147. Copyright 2000 by Elsevier. Adapted with permission
(A)

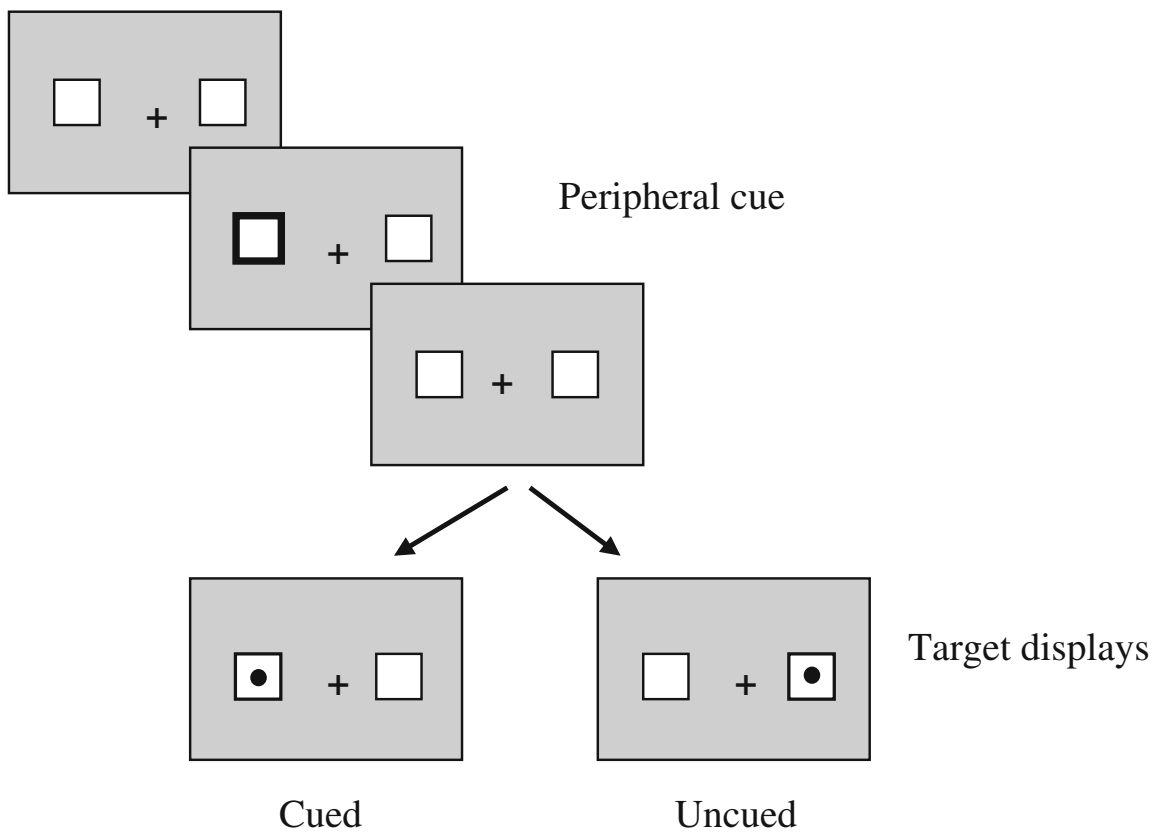

(B)

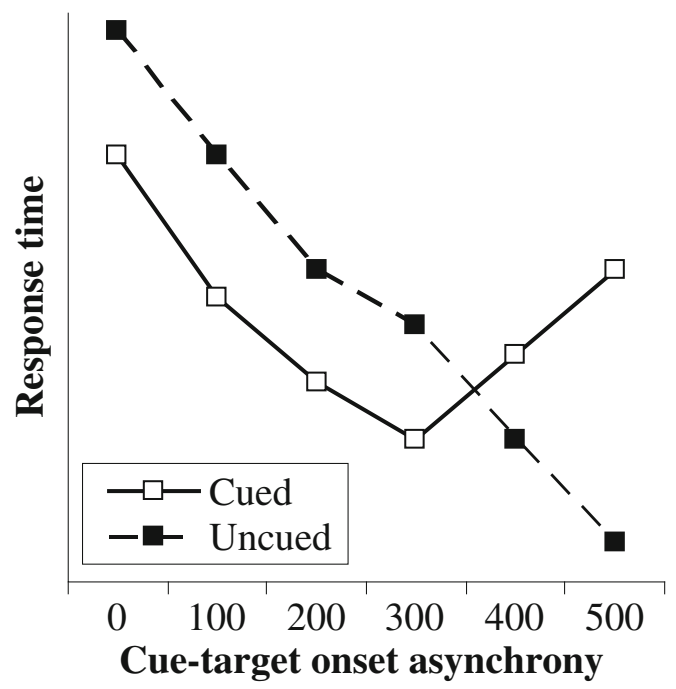

intervals of 300-3,000 ms (e.g., Samuel \& Kat, 2003), RTs are slower for cued than for uncued targets. This later effect of slowing of RTs to previously attended locations is known as inhibition of return, or IOR (e.g., Klein, 1988; Posner \& Cohen, 1984; Posner, Rafal, Choate, \& Vaughan, 1985).

\section{What is meant by facilitation and inhibition of return?}

It is frequently assumed that the RT benefits at short cuetarget intervals, and RT costs at longer cue-target intervals, reflect the complementary processes of facilitation and inhibition. On the one hand, facilitation as a theoretical construct may be construed as a cognitive process associ- ated with excitation at the locus of sensory information (e.g., Houghton \& Tipper, 1994; Moran \& Desimone, 1985). Similarly, inhibition may be considered as a process that suppresses processing of sensory information or responses to it (e.g., Kingstone \& Pratt, 1999; Taylor \& Klein, 2000).

A key research question is how these two fundamental processes operate and interact during attentional selection. There is now general agreement that spatial cueing can produce parallel facilitatory and inhibitory signals, and that responses to subsequent targets may reflect effects arising from the interaction of the two signals during target processing. This view is supported by both psychophysical (e.g., Ro \& Rafal, 1999; Tassinari, Aglioti, Chelazzi, Peru, \& Berlucchi, 1994; Tassinari \& Berlucchi, 1993) and 
neurophysiological (e.g., Mevorach, Humphreys, \& Shalev, 2006) studies. Given the independence of facilitation and inhibition, the relative speeding or slowing of target detection RTs may not necessarily reflect the operation of either a facilitatory or an inhibitory process, but rather the temporal combination of the two parallel signals (e.g., Tassinari et al., 1994; see also the review by Klein, 2000). For this reason, throughout this article, the terms facilitatory and IOR effects are used to refer to the relative speeding or slowing of RTs, respectively, without assuming a priori that each effect derives uniquely from either a single facilitatory enhancement or inhibitory suppression of stimulus processing.

\section{Representations mediating spatial cueing: space and objects}

Space-based effects of spatial cueing

The spatial cueing paradigm was initially used to gather evidence that attention operates on space-based representations, whereby information is represented as organised according to its location in space, resulting in biased sensory processing for events at attended locations relative to other locations (e.g., Downing \& Pinker, 1985; Eriksen \& Hoffman, 1972; Posner, Snyder, \& Davidson, 1980). The notion of a spatial representation, however, is far from a unitary concept. Many different spatial regions and relations need to be represented, such as the space between objects, the location that an object occupies within the world, the space within an object's contours (e.g., a teacup), or the space between an object and the observer (see Robertson, 2004, for a discussion). Similarly, different components of spatial representations are imposed by the neural architecture of the visual system. Irrespective of whether we are dealing with space within or between objects, or how this space is ultimately implemented neurally, in space-based representations spatial regions and relations are explicitly encoded and are considered to provide the route to selection of information at the location occupied, while form or structure is implicit within the spatial medium, only influencing selection by way of grouping locations (e.g., Vecera \& Farah, 1994).

Spatial cueing effects between objects In early spatial cueing studies, where the cue and target (or placeholders containing them) were the only objects in the display, both facilitatory and IOR effects were influenced by where the cue and target appeared, as well as by their spatial separation. Facilitatory cueing effects weaken as cue-target distance increases, both in two-dimensional space (e.g., Egly \& Homa, 1991; LaBerge, 1983; LaBerge \& Brown,
1989; Shulman, Remington, \& McLean, 1979; Tsal, 1983; Zimba \& Hughes, 1987) and in depth (e.g., de Gonzaga Gawryszewski, Riggio, Rizzolatti, \& Umiltà, 1987; Downing \& Pinker, 1985). Similarly, IOR effects can be weakened by cue-target separation in two-dimensional space (e.g., Bennett \& Pratt, 2001; Berlucchi, Tassinari, Marzi, \& Di Stefano, 1989; Klein, Christie, \& Morris, 2005; Maylor \& Hockey, 1985; Snyder, Schmidt, \& Kingstone, 2001), as well as by whether the cue and target appear on the same side of either the vertical or horizontal visual meridians (e.g., Berlucchi et al., 1989; Tipper et al., 1997). These findings led to an emphasis on selective attention's spatial nature, with such metaphors as a spotlight moving through space lighting an area of the visual field (e.g., Eriksen \& Eriksen, 1974; Posner et al., 1980; see the review by Cave \& Bichot, 1999), zoom lenses (e.g., Eriksen \& St James, 1986; Eriksen \& Yeh, 1985), or spatial gradients (e.g., Downing \& Pinker, 1985; LaBerge \& Brown, 1989).

Studies investigating the spatial coordinates that spatial cueing operates within, have shown space to be coded in different frames of reference (Fig. 2). Evidence has shown that information can be coded relative to an axis defined in relation to the viewer (Fig. 2a) or by the position in the environment relative to a landmark in the visual display (e.g., Maylor, 1985; Posner \& Cohen, 1984). Later studies presenting cues and targets at different locations in 3-D space provided evidence for the viewer-centred coding of space between objects (cue and target; e.g., Andersen, 1990; Andersen \& Kramer, 1993; Arnott \& Shedden, 2000; Gawryszewski et al., 1987; Downing \& Pinker, 1985).

Spatial cueing effects within objects Later spatial cueing studies started to introduce object contours that surrounded both the cue and target and to examine the effect of such object contour presence on the distribution of spatial attention (e.g., Egly et al., 1994; Hollingworth, Maxcey-Richard, \& Vecera, 2011; Reppa, Fougnie, \& Schmidt, 2010; Robertson $\&$ Kim, 1999). These studies have shown that within-object locations can be coded in object-centred frames of reference (Fig. 2c), defined relative to one of the object's axes (e.g., elongation or symmetry), and that object-associated cueing effects remain unchanged, irrespective of changes in other, viewer-centred frames of reference (e.g., Gibson \& Egeth, 1994; Reppa et al., 2010; Umiltà, Castiello, Fontana, \& Vestri, 1995). For instance, Umiltà et al. showed that facilitatory cueing effects were tied to the cued location within an object, irrespective of whether the cued location had changed relative to the viewer.

While within-object locations can be coded in objectcentred frames of reference, studies investigating how attention spreads across the bounded surface of an object have shown that within-object shifts are similar to un- 
A. Location-based selection in a viewer-centred reference frame
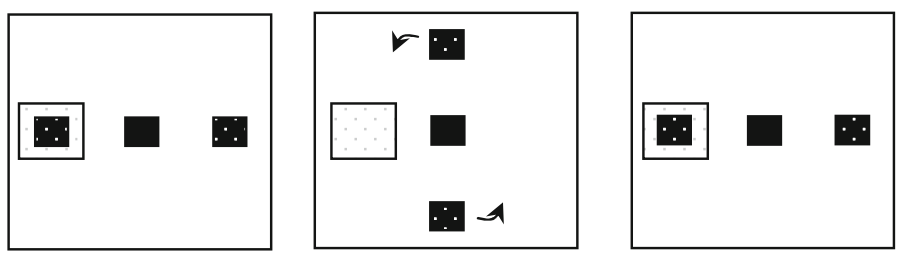

B. Object-based selection in a scene-based reference frame
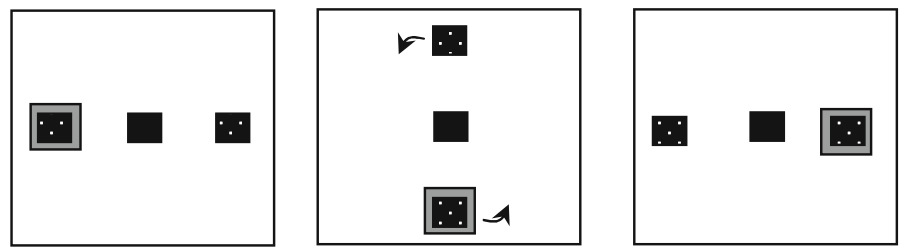

C. Location-based selection in an object-centred reference frame
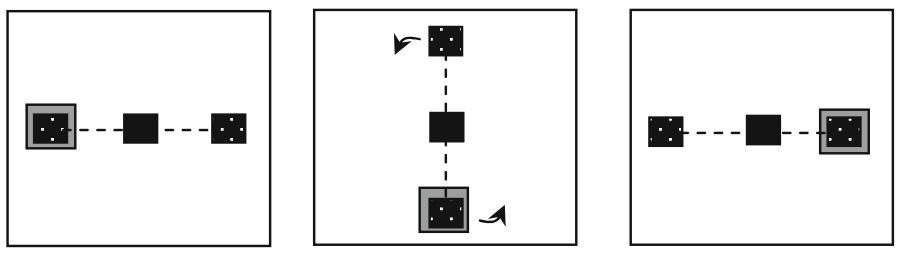

D. Location- and object-based selection in viewer- centred and scene-based reference frames
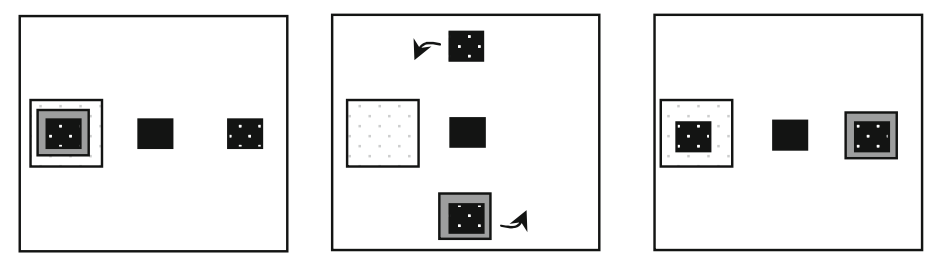

E. Location- and part-based selection in viewer- and object-centred reference frames
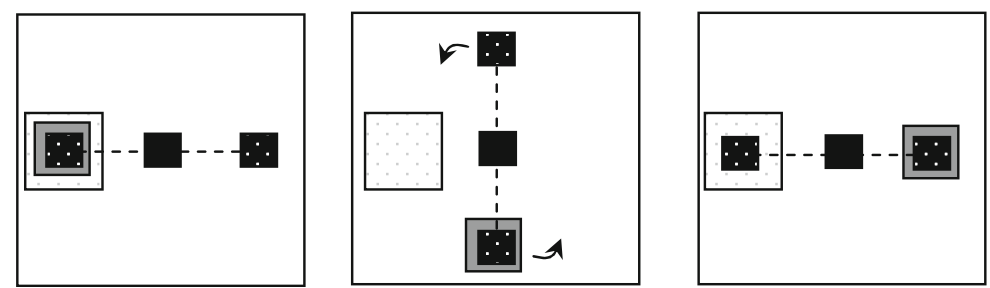

Fig. 2 Illustration of the different frames of reference that spatial cueing effects might operate under. The first column illustrates the initial positions of the cue and target stimuli. The second and third columns illustrate the cue and target positions following plane rotation. Light grey areas indicate spatial cueing effects associated

bounded between-object shifts. For instance, cueing effects can increase with increasing cue-target distance, both in the space between different objects (e.g., Downing \& Pinker, with the environmental location relative to the viewer (viewer-centred frames of reference yielding location-based spatial cueing effects). Dark grey areas indicate spatial cueing effects associated with the object (scene-based frames of reference yielding object-based spatial cueing effects)

1985) and in the space within objects (e.g., Egly et al., 1994; Hollingworth et al., 2011). Furthermore, just as with space between objects, locations in the space along an object's 
surface can be coded in viewer-centred coordinates, with shifts of attention away from the viewer leading to larger facilitatory effects than does shifting attention towards the viewer (e.g., Reppa et al., 2010). Therefore, shifts of attention across object space can resemble shifts of attention in the featureless, unbounded space between objects. This finding has led some theorists to propose that cueing effectsfacilitatory and inhibitory - are solely mediated by representations of spatial locations. These accounts will be discussed in a later section, but first evidence for object-based spatial cueing effects will be discussed.

\section{Object-based effects of spatial cueing}

Although space is all around us, our everyday experience is mostly related to things occupying space-for instance, objects. In line with common-sense experience and increased ability to present realistic objects, eventually spatial cueing studies started to examine the possibility that attention may operate on representations of objects, as opposed to simply representations of the space they occupy. Indeed, the introduction and manipulation of object contours as stimuli in spatial cueing tasks had significant consequences for the pattern, presence, and magnitude of spatial cueing effects (e.g., Egly et al., 1994; Reppa et al., 2010; Robertson \& Kim, 1999; Tipper et al., 1991).

Starting with the seminal work of Tipper, Driver, and Weaver (1991) and Egly, Driver, and Rafal (1994) using moving and static object displays, respectively, spatial cueing studies have shown that a target detection or discrimination response following a cue can be influenced by the presence of object boundaries defining a uniform contour. In moving object displays, cueing effects can remain tied to the cued object, irrespective of whether it has changed location in space defined in viewer-centred coordinates (e.g., Tipper et al., 1991; Tipper, Weaver, Jerreat, \& Burak, 1994). In static object displays, cueing effects can be tied to the selection of object contours: Targets appearing within the same contour as the cue are responded to faster than are targets appearing within a different contour from the cue (e.g., Egly et al., 1994; He \& Nakayama, 1995; Jordan \& Tipper, 1999; Vecera, 1994). These findings, reviewed in detail later, have raised the possibility that visual selection can be objectbased, selecting representations of objects rather than representations that are organised strictly spatially, regardless of the object contours present in the visual input.

The term object-based is, in itself, debated. According to the most common meaning of object-based attention, attentional selection might operate on discrete perceptual groups embodying their own visual properties, including the space they occupy, over other groups. It is this usage that the present review will ascribe to. In contrast, it is sometimes considered that the notion of spatially invariant object-centred representations - that is, representations of objects independently of the space they occupy - should be the hallmark of object-based attention (e.g., Vecera, 1994; Vecera \& Farah, 1994). However, the hypothesis of spatially invariant object representations is based on one set of theories in object recognition, namely a subset of structural description theories (e.g., Biederman, 1987; Marr, 1982), and has received limited empirical support. Unsurprisingly, tests of this hypothesis in the selective attention literature have similarly failed to find support (e.g., Kramer, Weber, \& Watson, 1997; Schendel et al., 2001).

The earliest evidence for object-based selection and for the notion that object representations may underlie such selection in the spatial cueing paradigm comes from studies that have used moving object displays. These are reviewed next.

\section{Object-based cueing effects in moving object displays}

\section{Moving object displays procedure}

One challenging design issue for studies of object-based attention has been dissociating the cueing effects associated with display objects from the effects associated with the locations that they occupy. In studies using moving displays, the term object refers to spatially and temporally contiguous contours, such as might constitute an object file or token (e. g., Kahneman, Treisman, \& Gibbs, 1992). One way to separate the effects due to object versus location has been to cue an object occupying a specific location and then to change the location of the cued object via rotational (e.g., Tipper et al., 1991) or translational (e.g., Christ, McCrae, \& Abrams, 2002; Ro \& Rafal, 1999; Soto \& Blanco, 2004) motion, thus maintaining the object's spatiotemporal continuity. Following a back-to-centre cue, participants are subsequently asked to detect a target that appears on the previously cued object at its new location, or at the cued location, which is now occupied by a different object that was not previously cued (see Fig. 3). The rationale is that if selection only implicates representations of spatial locations coded solely relative to the viewer, then cueing benefits or costs should not be found for targets that appear on the object after it has moved to a new location (Fig. 2a). Conversely, if selection implicates representations of objects independently of their spatial location, then cueing benefits or costs should be observed even if the previously cued object has moved to a different location (Fig. 2b).

Evidence for object-based representations from moving-object studies

Studies in selective attention have used the moving-objects method to examine how objects influence spatial cueing 
Fig. 3 Examples of moving object displays. In the $90^{\circ}$ rotation condition, the target appears at an uncued location but in the cued object. In the $180^{\circ}$ rotation condition, the target appears at the cued location and in the uncued object. IOR in both conditions was calculated as the RT for the uncued object minus the RT for the cued object. Adapted from "Object-Centred Inhibition of Return of Visual Attention" by S. P. Tipper, J. Driver, \& B. Weaver, 1991, Quarterly Journal of Experimental Psychology, 43A, pp. 289-298. Copyright 1991 by Taylor \& Francis. Adapted with permission

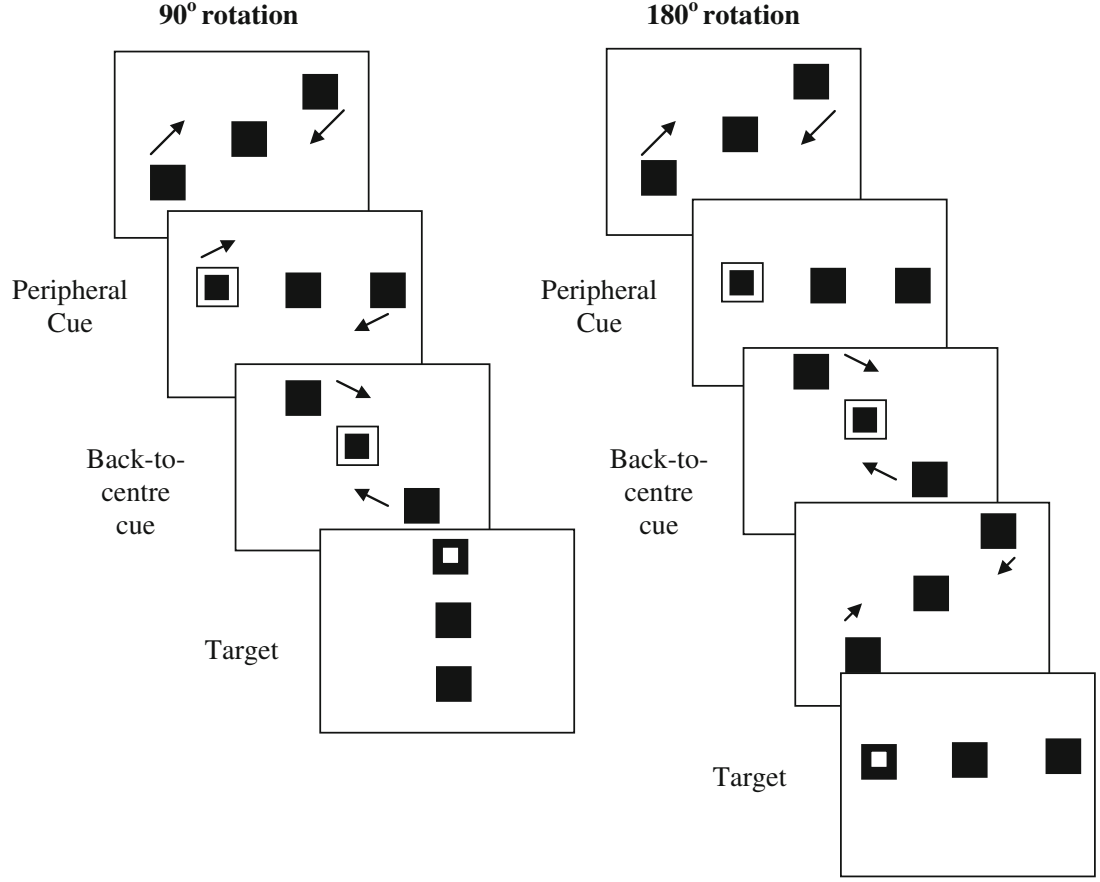

effects independently of their spatial location (e.g., Abrams \& Dobkin, 1994; Behrmann \& Tipper, 1999; Christ et al., 2002; Gibson \& Egeth, 1994; Kahneman et al., 1992; Lamy \& Tsal, 2000; McCrae \& Abrams, 2001; Müller \& von Mühlenen, 1996; Ro \& Rafal, 1999; Soto \& Blanco, 2004; Tipper \& Behrmann, 1996; Tipper et al., 1991; Tipper, Jordan, \& Weaver, 1999; Tipper et al., 1994; Umiltà et al., 1995; Vivas, Humphreys, \& Fuentes, 2008; Weaver, Lupiáñez, \& Watson, 1998). This method has been primarily used to examine IOR effects, with fewer studies examining facilitatory effects (e.g., Lamy \& Tsal, 2000; Soto \& Blanco, 2004). In their original study, Tipper et al. (1991) used a variant of the spatial cueing paradigm in which two squares were presented peripherally on either side of a central (fixation) placeholder. One of the two peripheral squares was briefly cued before both squares started to rotate around the central placeholder by $90^{\circ}$ or $180^{\circ}$ (Fig. 3). Subsequent target detection was slowed for the cued square, despite its having moved to a new location, providing evidence compatible with the idea that IOR cueing effects can be object-based. This was the first demonstration of object-based IOR showing that IOR can be associated with a scene-based frame of reference, where each object occupies a location in a scene that may be separate from its location in other, viewer-centred frames of reference.

Later, in studies examining facilitatory cueing effects, similar results emerged showing that facilitatory effects can be associated both with space-based and with object-based representations of the same display as long as the objects maintained their spatiotemporal continuity (e.g., Lamy \& Tsal, 2000; Soto \& Blanco, 2004), as opposed to when they did not (e.g., Schendel et al., 2001), and regardless of whether or not they were relevant to the task (e.g., Soto \& Blanco, 2004).

Soon after the first demonstration of object-based (scenebased) IOR effects by Tipper et al. (1991), studies started showing that objects can influence selective attention by defining a coordinate system within which other stimuli/ events can be coded (see Fig. 2c). Evidence that selective attention can operate within object-centred frames of reference has come from studies with both neuropsychologically impaired (e.g., Behrmann \& Tipper, 1994, 1999; Humphreys \& Riddoch, 1994, 1995; Tipper \& Behrmann, 1996) and healthy (e.g., Gibson \& Egeth, 1994; ReuterLorenz, Drain, \& Hardy-Morais, 1996; Tipper et al., 1999; Umiltà et al., 1995) adults. In the spatial cueing literature, both facilitatory (e.g., Umiltà et al., 1995) and IOR (e.g., Gibson \& Egeth, 1994; Tipper et al., 1999) cueing effects have been observed within object-centred frames of reference. These studies have shown that the two cueing effects can be associated with part of an object as it moves through space, as opposed to being tied to a fixed environmental location relative to the viewer.

Multiple types of representation can be active in parallel

Both facilitatory and IOR effects have been shown to be mediated by representations coded in more than one frame of reference during the same experiment. In spatial cueing studies with healthy adults, viewer- and object-centred frames of reference were found to be simultaneously active and to influence spatial cueing (see Fig. 2e), as demon- 
strated by Gibson and Egeth, (1994; see Table 1). They used displays of a single brick rotating in depth to examine whether locations defined with respect to the brick would elicit IOR similar in magnitude to that from locations in the environment fixed with respect to the viewer. They found significant IOR for locations defined both with respect to the viewer (viewer-centred) and the object (object-centred).

Just as object- and viewer-centred representations may coexist, scene-based and viewer-centred representations may be active in parallel within a single experimental setting (Fig. 2d; e.g., Tipper et al., 1999; Tipper et al., 1994; Weaver et al., 1998). Tipper, Weaver, Jerreat, and Burak (1994; see Table 1) found evidence for scene-based (objectbased) and viewer-centred cue costs: IOR effects were significant for targets appearing on the cued square as well as for targets appearing at the cued location (now occupied by a different object). Furthermore, IOR effects were larger when the object displays were static as opposed to when they were moving, suggesting cumulative IOR effects arising from the encoding of locations in both viewercentred and scene-based frames of reference.

Not only can different frames of reference be simultaneously active, but they can independently mediate facilitatory and IOR effects. Tipper, Jordan, and Weaver (1999) used a three-square display (shown in Table 1). In the scene-based condition, the three squares were unconnected, encouraging the percept of three separate objects in a scene. In the objectcentred condition, the squares were connected by lines, encouraging the percept of a single large object (e.g., a triangle). In the scene-based condition, a significant IOR effect occurred both for targets appearing on the cued object and for those appearing at the cued location (now occupied by a different object), replicating previous evidence for the simultaneous operating of IOR within scene-based and viewer-centred representations (e.g., Tipper et al., 1991). However, in the object-centred condition - where the squares were connected with straight lines to encourage the percept of a single object - a different pattern of results emerged. While there was a significant IOR effect for the cued object part (object-centred or part-based IOR), for an uncued object part (one of the uncued squares appearing at the cued location), rather than viewer-centred/location-based IOR, there was a significant facilitatory effect.

The Tipper et al. (1999) study was of critical importance for two reasons. First, it was an early demonstration that facilitatory and inhibitory processes mediating covert orienting can operate in parallel on different representations arising from the same stimulus display. When a single object was perceived, there was significant IOR for the cued part of the object, suggesting that IOR resulted from an object-centred (part-based) representation of the display. Meanwhile, there was significant facilitation for the cued location in the environment, suggesting that the facilitatory cueing effect was mediated by a viewer-centred (environmental-location-based) representation.

The second reason Tipper et al. (1999) was important is that environmental-location-based costs were eliminated in the presence of significant object-centred costs. This suggests that when perceptual information encourages a different, complex organisation of the display - the scene is interpreted as a single object as opposed to three independent objects - earlier spatial representations may no longer be consulted or influence selective attention to the same extent. In the case of Tipper et al. (1999), the representation of locations in a viewer-centred frame no longer mediated IOR effects, even though it was available for the processes producing facilitatory effects.

Some boundary conditions in finding object-based effects in moving object displays

The majority of studies examining spatial cueing effects in moving object displays have reported significant objectbased IOR effects. Nevertheless, it has been noted in the literature that certain experimental parameters may either favour object-based facilitatory effects over object-based IOR effects, or even eliminate both effects (e.g., Ro \& Rafal, 1999). To date, the influential boundary conditions affecting the likelihood of observing object-based IOR in moving object displays have included stimulus and pragmatic factors. A nonsalient back-to-centre cue (Ro \& Rafal, 1999), lack of or ambiguous spatiotemporal continuity of an object (e.g., Lamy \& Tsal, 2000; Schendel et al., 2001), and ambiguous object cueing (Tipper et al., 1994) have all been shown to diminish object-based IOR in moving object displays. Similarly, high levels of experience or practice (e.g., Müller \& von Mühlenen, 1996; Weaver et al., 1998) have been found to reduce object-based effects. Finally, observations implicating facilitatory and inhibitory processes as coexisting have suggested that their net contributions to response time may conceal object-based effects, as seemed to occur in Ro and Rafal (1999).

In a moving-object experiment, Tipper et al. (1994, Exp. 6; see Table 1) found that if the cued object (one of the static or moving squares) was ambiguous due to occlusion at the time of cueing, no significant IOR effects emerged for that object. However, IOR effects were significant for objects that were visible at the time of cueing. This finding has been replicated in later experiments (e.g., Takeda \& Yagi, 2000) and suggests that cueing effects are mediated by explicit representations about the object that was cued. Similar findings and conclusions have been drawn from studies that have examined the facilitatory effect of spatial cueing (e.g., Lamy \& Tsal, 2000; Soto \& Blanco, 2004) by manipulating the spatiotemporal continuity of the object. For instance, Lamy and Tsal (2000, Exp. 2) found 
Table 1 Summary of IOR cueing effects (in milliseconds) in moving object studies reported as a function of object type, target duration, stimulus onset asynchrony (SOA), and most recent cue-to-target interval (MRCTI)

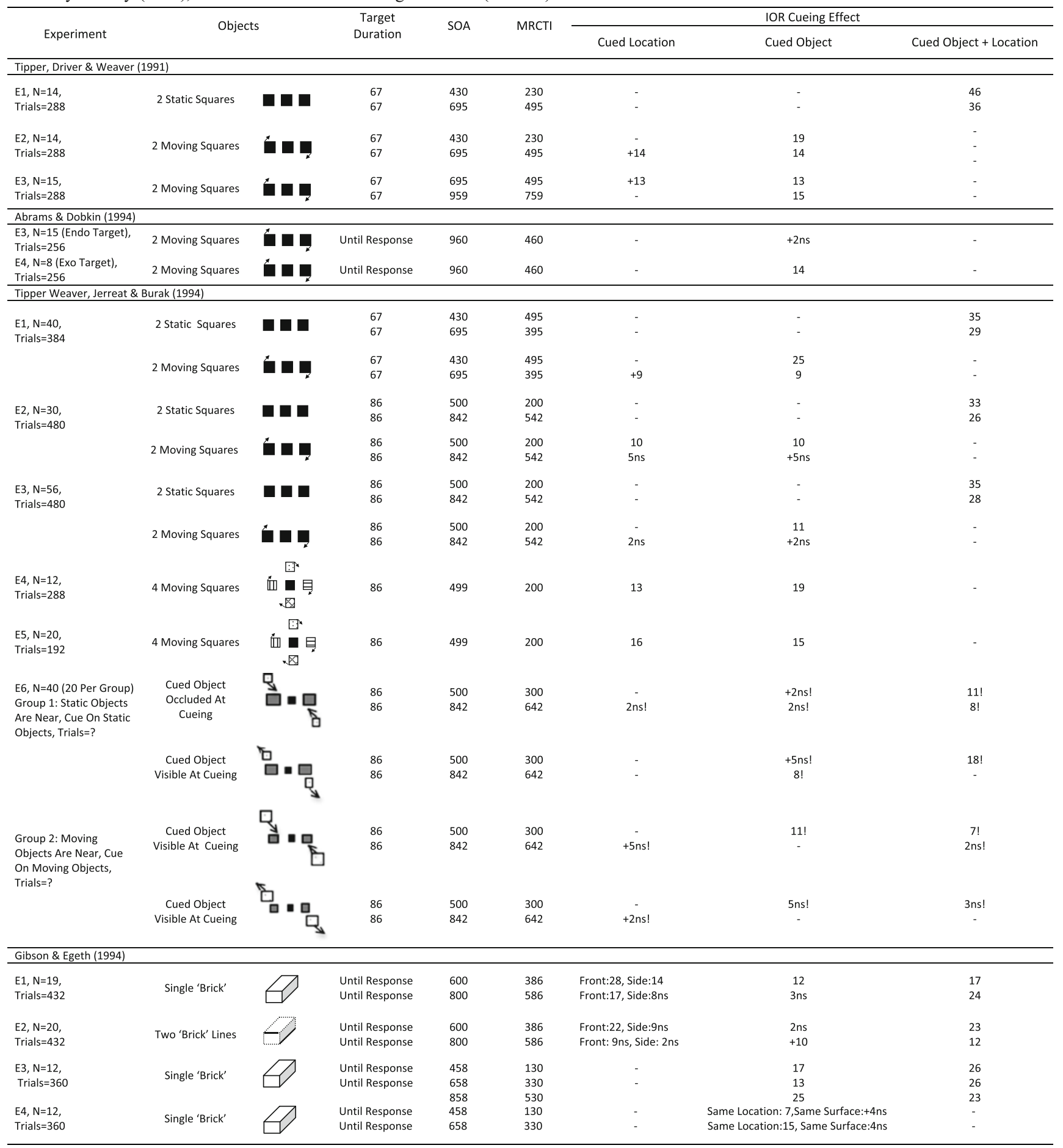

significant object-based effects only when the object in which the cue appeared maintained its spatiotemporal continuity in the interval between cue and target presentation by smoothly moving to a different position before the target was presented. In contrast, when spatiotemporal continuity was absent and the state of object files was ambiguous because the cued object abruptly appeared in the uncued location, no object-based facilitatory effect occurred for targets appearing within it (Lamy \& Tsal, 2000, Exp. 1; see also Schendel et al., 2001). These findings reaffirm what one intuitively might expect: that the presence and visibility of an object - as a single spatiotemporal entity defining an object file - is a necessary requirement for object-based effects to emerge. 
Table 1 (continued)

\begin{tabular}{|c|c|c|c|c|c|c|c|}
\hline \multirow[b]{2}{*}{ Experiment } & \multirow{2}{*}{ Objects } & \multirow{2}{*}{$\begin{array}{l}\text { Target } \\
\text { Duration }\end{array}$} & \multirow{2}{*}{ SOA } & \multirow{2}{*}{ MRCTI } & \multicolumn{3}{|c|}{ IOR Cueing Effect } \\
\hline & & & & & Cued Location & Cued Object & Cued Object + Location \\
\hline \multicolumn{8}{|c|}{ Müller \& Mühlenen (1996) } \\
\hline \multirow{12}{*}{$\begin{array}{l}\mathrm{E} 1, \mathrm{~N}=10 \\
\text { Trials }=2880 \\
\text { (1440 Per Display) }\end{array}$} & \multirow{6}{*}{2 Static Squares } & Until Response & 100 & 0 & - & - & +9 ns \\
\hline & & Until Response & 250 & 150 & - & - & 1ns \\
\hline & & Until Response & 400 & 300 & - & - & 6 ns \\
\hline & & Until Response & 700 & 200 & - & - & 14 \\
\hline & & Until Response & 1000 & 400 & - & - & 18 \\
\hline & & Until Response & 1300 & 700 & - & - & 21 \\
\hline & \multirow{6}{*}{2 Moving Squares } & Until Response & 100 & 0 & - & $+3 \mathrm{~ns}$ & - \\
\hline & & Until Response & 250 & 150 & - & $+4 \mathrm{~ns}$ & - \\
\hline & & Until Response & 400 & 300 & - & +22 & - \\
\hline & & Until Response & 700 & 200 & - & +13 & - \\
\hline & & Until Response & 1000 & 400 & - & $8 \mathrm{~ns}$ & - \\
\hline & & Until Response & 1300 & 700 & - & 14 & - \\
\hline \multirow{8}{*}{$\begin{array}{l}E 2, N=8, \\
\text { Trials }=3520\end{array}$} & \multirow{2}{*}{2 Static Squares } & Until Response & 100 & 0 & - & - & Left Cue: +2 ns, RightCue:+8ns \\
\hline & & Until Response & 1300 & 700 & - & - & Left Cue: 27 , Right Cue: 5 ns \\
\hline & \multirow{6}{*}{2 Moving Squares } & Until Response & 100 & 0 & - & Left Cue: +5ns, Right Cue: +31 & \\
\hline & & Until Response & 250 & 150 & - & Left Cue: +4 ns, Right Cue: Ons & - \\
\hline & & Until Response & 400 & 300 & - & Left Cue: +18 , Right Cue: 11 ns & - \\
\hline & & Until Response & 700 & 200 & - & Left Cue: +2 ns, Right Cue: 6 ns & - \\
\hline & & Until Response & 1000 & 400 & - & Left Cue: 18 , Right Cue: +14 & - \\
\hline & & Until Response & 1300 & 700 & - & Left Cue: 16 , Right Cue: 2 ns & - \\
\hline \multirow{5}{*}{$\begin{array}{l}E 3, N=9, \\
\text { Trials }=7,200\end{array}$} & \multirow{5}{*}{2 Moving Squares } & Until Response & 100 & 0 & - & Left Cue:+19, Right Cue:+30 & - \\
\hline & & Until Response & 400 & 300 & - & Left Cue:+10ns, Right Cue: $14 \mathrm{~ns}$ & - \\
\hline & & Until Response & 700 & 200 & - & Left Cue: $+3 n s$, Right Cue: 3 ns & - \\
\hline & & Until Response & 1000 & 400 & - & Left Cue: $10 \mathrm{~ns}$, Rightcue: $+13 \mathrm{~ns}$ & - \\
\hline & & Until Response & 1300 & 700 & - & Left Cue: 13 ns, Right Cue: +8 ns & - \\
\hline $\mathrm{E} 5, \mathrm{~N}=16$ & \multirow{2}{*}{2 Static Squares } & Until Response & 100 & 0 & - & - & Left Cue: +26 , Right Cue: +26 \\
\hline Trials $=$ ? & & Until Response & 1300 & 700 & - & - & Left Cue: 15 , Right Cue: 19 \\
\hline \multicolumn{8}{|c|}{ Tipper, Rafal, Reuter-Lorenz, Starrveldt, Ro, Egly \& Danzinger (1997) } \\
\hline$E 1, N=20$, & \multirow{2}{*}{2 Moving Squares } & 86 & 500 & 300 & - & Within: 8 , Between: 9 & - \\
\hline Trials $=336$ & & 86 & 842 & 642 & - & - & 1ns \\
\hline E2, Split-Brain Patients & \multirow{2}{*}{2 Moving Squares } & 86 & 500 & 300 & - & Within: 16 , Between: +18 & - \\
\hline $\mathrm{N}=2$, Trials $=192 \& 120$ & & 86 & 842 & 642 & - & - & $11 \mathrm{~ns}$ \\
\hline $\begin{array}{l}\text { E2, Control } \mathrm{N}=9 \text {, } \\
\text { Trials }=168\end{array}$ & 2 Moving Squares & 86 & 500 & 300 & - & Within: 22, Between: 21 & - \\
\hline $\begin{array}{l}\text { E3, Split-Brain Patient } \\
N=1, \text { Trials }=1120\end{array}$ & 4 Static Squares & 86 & 500 & 300 & - & Within: 41, Between: 34 & - \\
\hline \multicolumn{8}{|c|}{ Weaver, Lupiáñez \& Watson (1998) - Mean Cueing Effects Reported Across 12 Blocks Of Trials } \\
\hline $\begin{array}{l}E 1, N=16 \\
\text { Trials }=1080\end{array}$ & 3 Moving Squares & 57 & 630 & 372 & $\begin{array}{c}4.6:(15,4,3,6,0,2,5,2,3 \\
1,4,10)\end{array}$ & 4.8: $(23,8,5,5,3,2,2,+1,2,0,2,6)$ & - \\
\hline $\begin{array}{l}E 2, N=16 \\
\text { Trials }=1080\end{array}$ & 3 Static Squares & 57 & 630 & 372 & - & - & $\begin{array}{l}20:(57,32,25,20,23,14,15,14 \\
11,11,8,11)\end{array}$ \\
\hline \multicolumn{8}{|c|}{ Tipper, Jordan \& Weaver (1999) } \\
\hline & & & & & & & \\
\hline $\begin{array}{l}\mathrm{E} 1, \mathrm{~N}=20 \\
\text { Trials }=300\end{array}$ & $\begin{array}{l}3 \text { Moving Squares } \\
\text { Unlinked }\end{array}$ & 57 & 598 & 340 & 11 & 14.5 & - \\
\hline & $\begin{array}{l}3 \text { Moving Squares } \\
\text { Linked }\end{array}$ & 57 & 598 & 340 & +9 & 7 & - \\
\hline $\begin{array}{l}E 2, \mathrm{~N}=21 \\
\text { Trials }=300\end{array}$ & $\begin{array}{l}3 \text { Moving Squares } \\
\text { Unlinked }\end{array}$ & 57 & 598 & 340 & 15 & 15 & - \\
\hline & $\begin{array}{l}3 \text { Moving Squares } \\
\text { Linked }\end{array}$ & 57 & 598 & 340 & +8 & 13.5 & - \\
\hline $\begin{array}{l}E 3, N=16 \\
\text { Trials }=300\end{array}$ & $\begin{array}{l}3 \text { Moving Squares } \\
\text { Unlinked }\end{array}$ & 57 & 598 & 340 & 18 & 15 & - \\
\hline & $\begin{array}{l}3 \text { Moving Squares } \\
\text { Linked }\end{array}$ & 57 & 598 & 340 & $4 \mathrm{~ns}$ & 10 & - \\
\hline
\end{tabular}

Although object contours clearly play an important role in producing cueing effects, the mere presence of an object's outline contour is not sufficient to elicit objectbased effects in moving displays. One well-documented factor in the reduction or elimination of object-based IOR effects in moving-object studies is practice or repeated stimulus exposure within the spatial cueing task. Weaver, Lupiáñez, and Watson (1998) showed that, despite remaining significant, object-based and environmental-location-based IOR effects decreased in magnitude significantly and at 
Table 1 (continued)

\begin{tabular}{|c|c|c|c|c|c|c|c|}
\hline \multirow{2}{*}{ Experiment } & \multirow{2}{*}{ Objects } & \multirow{2}{*}{$\begin{array}{l}\text { Target } \\
\text { Duration }\end{array}$} & \multirow{2}{*}{ SOA } & \multirow{2}{*}{ MRCTI } & \multicolumn{3}{|c|}{ IOR Cueing Effect } \\
\hline & & & & & Cued Location & Cued Object & Cued Object + Location \\
\hline \multicolumn{8}{|c|}{ Ro \& Rafal (1999) - Short-Range Motion Condition Only Reported Here. } \\
\hline $\begin{array}{l}\mathrm{E} 1, \mathrm{~N}=12 \\
\text { Trials=288 } \\
\text { (No Fixation Cue) }\end{array}$ & 2 Moving Squares & 100 & 600 & 600 & - & +9 & - \\
\hline $\begin{array}{l}\mathrm{E} 2, \mathrm{~N}=15, \\
\text { Trials=288 } \\
\text { (Fixation Cue Coincided } \\
\text { With Start Of Motion) }\end{array}$ & 2 Moving Squares & 100 & 600 & 400 & - & +5 & - \\
\hline $\begin{array}{l}\mathrm{E} 3, \mathrm{~N}=16 \\
\text { Trials }=384 \\
\text { (No Fixation Cue) }\end{array}$ & 2 Moving Squares & 100 & 900 & 900 & - & +5 & - \\
\hline $\begin{array}{l}E 4, N=18 \text {, } \\
\text { Trials }=288 \text { (Fixation Cue } \\
\text { At End Of Motion) }\end{array}$ & 2 Moving Squares & 100 & 900 & 266 & - & -5 & - \\
\hline $\begin{array}{l}E 5, \mathrm{~N}=15 \\
\text { Trials=288 } \\
\text { (Large Fixation Cue) }\end{array}$ & 2 Moving Squares & 100 & 600 & 400 & - & -6 & - \\
\hline $\begin{array}{l}\mathrm{E} 6, \mathrm{~N}=18, \\
\text { Trials=288 (Large } \\
\text { Fixation Cue) }\end{array}$ & 2 Moving Squares & 100 & 600 & 600 & - & -5 & - \\
\hline \multicolumn{8}{|c|}{ Christ, Mccrae \& Abrams (2002) } \\
\hline \multirow{2}{*}{$\begin{array}{l}\mathrm{E} 1, \mathrm{~N}=12 \\
\text { Trials }=280\end{array}$} & \multirow{2}{*}{2 Static Squares } & Until Response & 633 & 333 & - & - & 34 \\
\hline & & Until Response & 633 & 333 & - & - & $1.5 \mathrm{~ns}$ \\
\hline \multirow{4}{*}{$\begin{array}{l}E 2, \mathrm{~N}=10 \\
\text { Trials }=288\end{array}$} & \multirow{2}{*}{2 Static Squares } & Until Response & 633 & 333 & - & - & 29 \\
\hline & & Until Response & 933 & 633 & - & - & 29 \\
\hline & \multirow{2}{*}{2 Moving Squares } & Until Response & 633 & 333 & - & - & 3 \\
\hline & & Until Response & 933 & 633 & - & - & 4 \\
\hline \multicolumn{8}{|c|}{ Vivas, Humphreys \& Fuentes (2008) - Mean Cueing Effects Are Reported For 'Up' And 'Down' Cued Targets Respectively } \\
\hline $\begin{array}{l}\text { E1, Control Group N=5, } \\
\text { Trials=200 }\end{array}$ & 2 Moving Squares & Until Response & 662 & 362 & - & $\begin{array}{l}\text { Up Target: } 12.5 \\
\text { Down Target: } 3.5\end{array}$ & - \\
\hline $\begin{array}{l}\text { E1, Patient Group } N=4 \text {, } \\
\text { Trials }=200\end{array}$ & 2 Moving Squares & Until Response & 662 & 362 & - & $\begin{array}{l}\text { Ipsi-Lesionally Cued Up Target: }+8 \text {, } \\
\text { Down Target: } 19 \\
\text { Contra-Lesionally Cued Up Target: } \\
46 \\
\text { Down Target: }+12\end{array}$ & - \\
\hline
\end{tabular}

Studies appear in chronological order. Arrows indicate the presence and direction of movement. In all studies cue duration was $100 \pm 14 \mathrm{~ms}$, the central fixation cue duration was $100 \pm 14 \mathrm{~ms}$, and the task was detection. Dash symbols (-) indicate that the condition was not applicable for that study, and plus symbols (+) indicate facilitatory effects. Question marks (?) denote that the information was unclear or not available, and exclamation marks (!) indicate that the value is an approximate calculation. Non-significant cueing effects are indicated by 'ns'

similar rates after the first 170 or so trials, disappearing over the course of over 1,000 trials. This finding could potentially explain the persistent lack of cued object IOR in Müller and von Mühlenen's (1996) experiments, whose participants completed 150 unrecorded practice trials before proceeding to complete several hundreds of recorded experimental trials (see Table 1 for study details). That practice can eliminate object-based IOR effects suggests that the simple presence of an object may not be sufficient to elicit or maintain a new, nonspatial representation of the display. Under conditions in which is it not relevant or useful to represent objects in the display, consulting representations of objects may be effectively abandoned in favour of other strategies, such as attentional tracking (e.g., Christ et al., 2002; Müller \& von Mühlenen, 1996) or filtering out detail as task-irrelevant (e.g., Broadbent, 1958) - instead, merely responding to low-spatialfrequency information. Perhaps, under such familiar situations, attentional load is decreased and representations of the visual scene are more sparse, leading to no need or benefit for object information to play a role in task performance.

To this point, we have surveyed the successes and failures in obtaining object-based cueing effects in moving object displays. It has emerged that the necessary conditions for observing object-based cueing effects are that the object be present and visible at the time of cueing and form a single, unambiguous spatiotemporal entity. The next section will review the successes and failures in obtaining object-based cueing effects using static object displays.

\section{Object-based effects in static object displays}

Factors known to influence the occurrence of object-based cueing effects in static object displays are related to both procedural and stimulus aspects of the experiment. To date, object-based facilitatory effects have been observed under conditions of both exogenous and endogenous cueing (e.g., Chen \& Cave, 2008; Goldsmith \& Yeari, 2003; but see Macquistan, 1997); in detection, discrimination, and identification tasks (e.g., Chen \& Cave, 2008; Egly et al., 1994; Moore, Yantis, \& Vaughan, 1998; Shomstein \& Behrmann, 2008; but see Brawn \& Snowden, 2000); under target position certainty and uncertainty (e.g., Chen \& Cave, 2008); when attention is narrowly or widely distributed (e.g., Chen \& 
Cave, 2008; Goldsmith \& Yeari, 2003); and in the presence of high and low probabilities of target location (e.g., Shomstein \& Behrmann, 2008; Shomstein \& Yantis, 2004).

Although robust with respect to the aforementioned manipulations, factors that relate to the viability - generation and maintenance - of object representations have been shown to influence both the presence and magnitude of cueing effects (e.g., Avrahami, 1999; Chen \& Cave, 2008; Law \& Abrams, 2002; Shomstein \& Behrmann, 2008). The present and the following two sections (Determinants of object-based facilitatory effects and determinants of object-based IOR effects in static displays) focus on the notion of objecthood in a number of different spatial cueing studies and on the relationship between the viability of object representations and the reliable observation of object-based cueing effects.

There is little consensus about what is meant by a perceptual object or an object of attention (e.g., Goldsmith, 1998; Pylyshyn, 2001). Nevertheless, the necessary - albeit not wholly sufficient - prerequisite for the observation of objectbased effects is the presence of physical or apparent contours (typically closed regions) in the visual display. Displays used to date have included outline and opaque rectangles and squares (e.g., Brown \& Denney, 2007; Christ et al., 2002; Egly et al., 1994; Iani, Nicoletti, Rubichi, \& Umiltà, 2001; Jordan \& Tipper, 1999; List \& Robertson, 2007; McAuliffe et al., 2001; Müller \& von Mühlenen, 1996; Reppa \& Leek, 2003, 2006; Shomstein \& Behrmann 2008; Theeuwes, Mathôt, \& Kingstone, 2010; Vecera, 1994), hockey-stick-like figures (e.g., Haimson \& Behrmann, 2001), overlapping objects (e.g., Behrmann, Zemel, \& Mozer, 1998; Brawn \& Snowden, 2000; Lavie \& Driver, 1996; Law \& Abrams, 2002; Moore et al., 1998), apparent rectangles and squares (e.g., Han, Wan, Wang, \& Humphreys, 2005; Jordan \& Tipper, 1999; Moore et al., 1998), thick lines (Robertson \& Kim, 1999), open parallel lines (e.g., Avrahami, 1999; Marino \& Scholl, 2005), outline ribbons (e.g., Avrahami, 1999), outline L-shapes (e.g., Leek, Reppa, \& Tipper, 2003; Possin, Filoteo, Song, \& Salmon, 2009; Reppa \& Leek, 2003, 2006), groups of dots forming rectangles (e.g., Marrara \& Moore, 2003), and outlines of 3-D objects (e.g., Bourke, Partridge, \& Pollux, 2006; Gibson \& Egeth, 1994). Some of the above object displays are shown in Tables 2, 3 and 4 .

If selection processes are mediated by representations of objects, the observation of object-based effects might reasonably be influenced by stimulus factors giving strong clues to object structure. As empirical studies have shown, object representations take time to develop and are built up incrementally at different spatial scales (e.g., Sekuler \& Palmer, 1992; Ullman, 1989). It seems reasonable to propose that the stronger the cues to "objecthood" or the other factors facilitating the construction of object repre-

Table 2 Summary of facilitatory cueing effects (in milliseconds) in studies that have varied time parameters

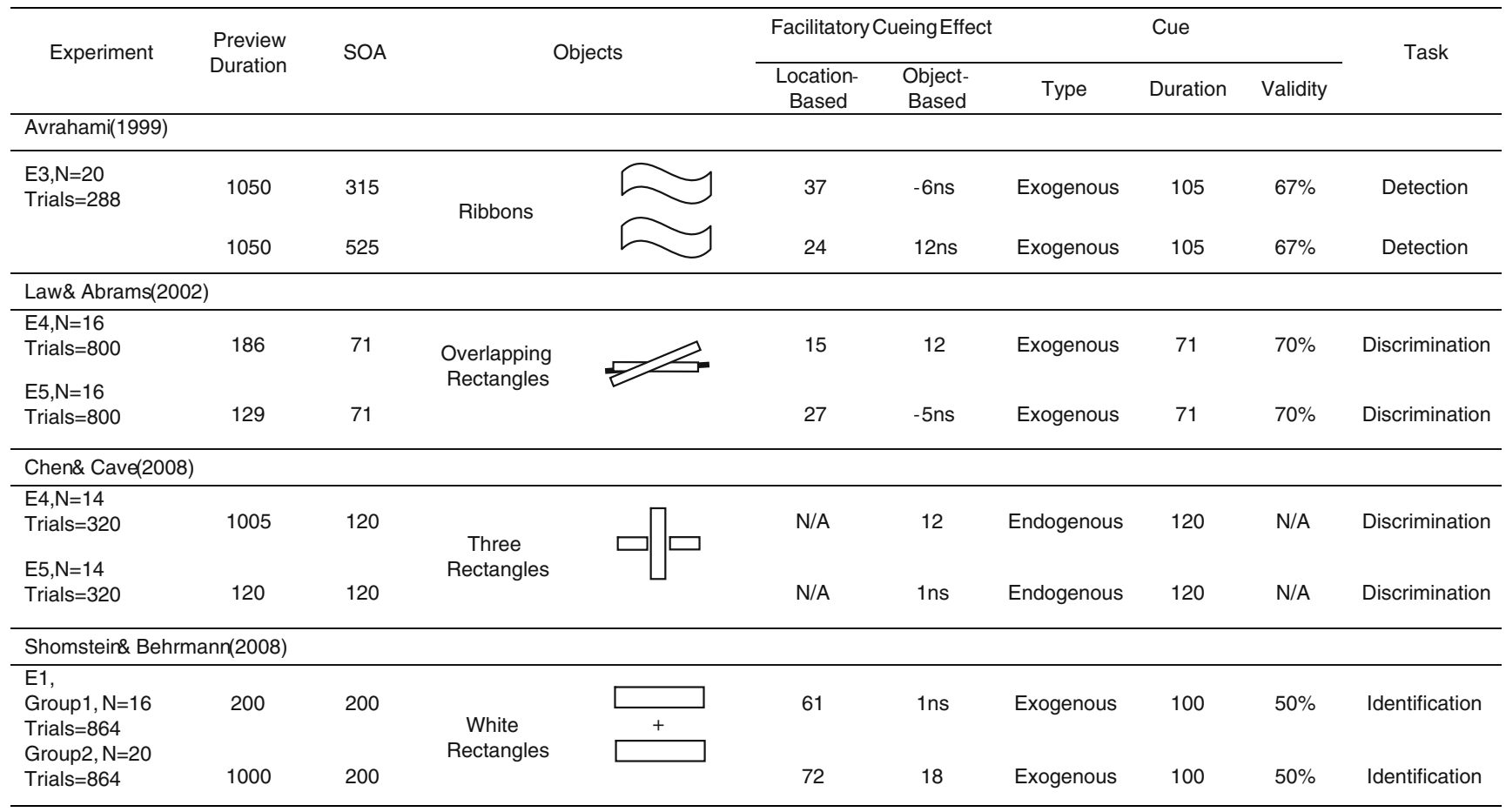

Studies appear in chronological order. Cueing effects are reported here as a function of preview duration (to the amount of time that the object display was visible before the cue-target sequence), SOA, object type, cue type, duration and validity, and task. 'N/A' indicates that the condition was not applicable. Non-significant effects are followed with 'ns' 
Table 3 Summary of facilitatory cueing effects (in milliseconds) in studies using variants of the Egly et al two-rectangle task with different object contour salience

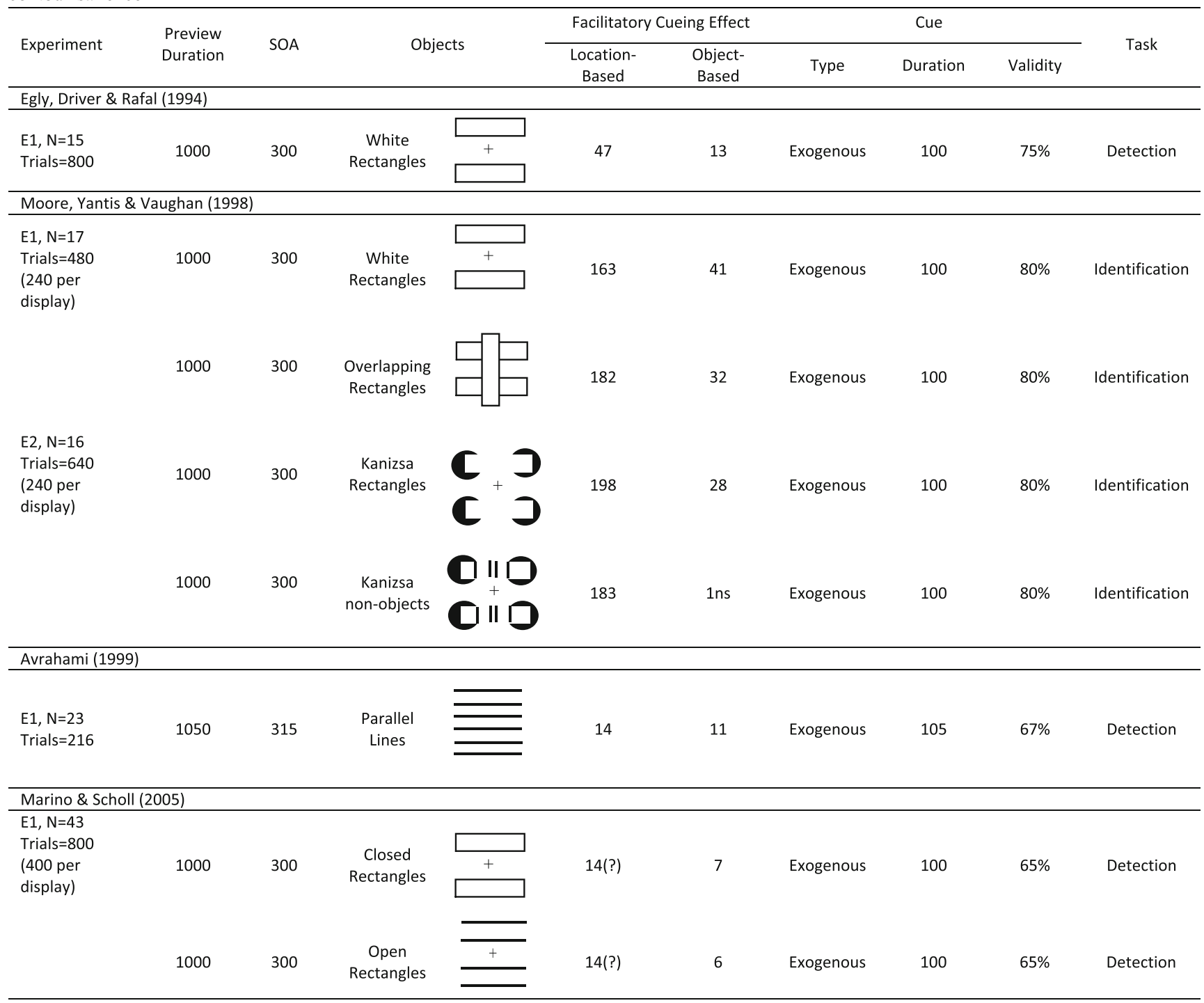

sentations (e.g., stimulus exposure duration, figure-ground distinctiveness, complexity, spatial scale, and spatial configuration), the faster and more effectively object representations might form and influence selective attention. The next section reviews evidence regarding the roles of factors that contribute to the generation and maintenance of object representations in producing reliable object-based facilitatory cueing effects.

\section{Determinants of object-based facilitatory effects}

Facilitatory effects are influenced by object presence

Substantial evidence from spatial cueing studies has demonstrated that the presence of object contours can constrain the spread of facilitatory cueing effects across the visual field. Using a two-rectangle paradigm, Egly et al. (1994) were the first to show that facilitatory effects in selective attention induced by a cue appearing on an object can extend to uncued locations of the same object relative to an uncued object. Since then, several other studies have shown that the presence of objects in a visual display can influence the distribution of facilitatory cueing effects (e.g., Abrams \& Law, 2000; Ariga, Yokosawa, \& Ogawa, 2007; Avrahami, 1999; Brown \& Denney, 2007; Chen, 1998; Chen \& Cave, 2008; Goldsmith \& Yeari, 2003; Haimson \& Behrmann, 2001; Hecht \& Vecera, 2007; Kravitz \& Behrmann, 2008; Lamy \& Egeth, 2002; Lamy \& Tsal, 2000; Law \& Abrams, 2002; Macquistan, 1997; Marino \& Scholl, 2005; Marrara \& Moore, 2003; Moore et al., 1998; Müller \& Kleinschmidt, 2003; Pratt \& Sekuler, 2001; 
Table 3 (continued)

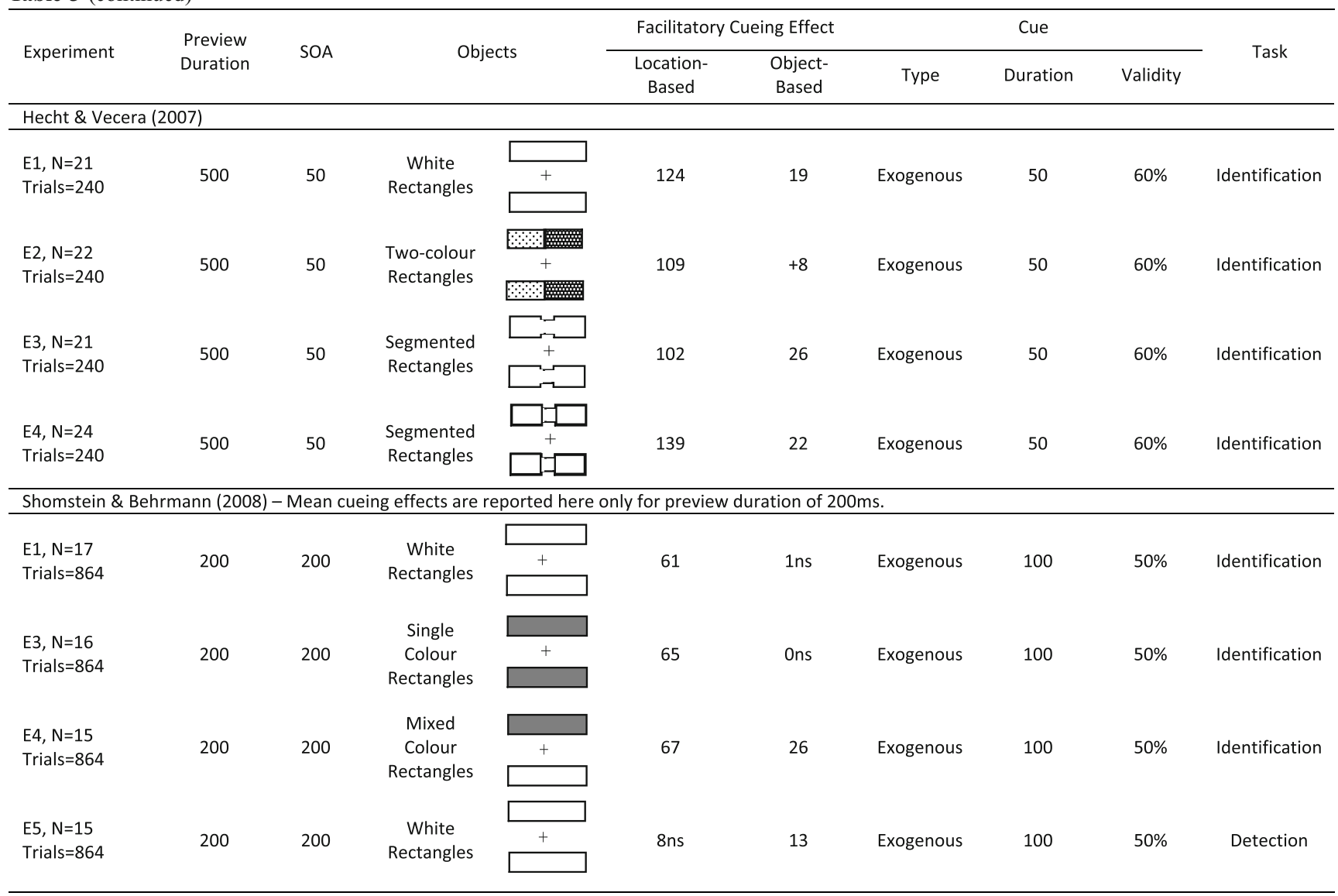

Studies appear in chronological order, with the Egly et al (1994) study present for comparison. Cueing effects are reported here as a function of preview duration, SOA, object type, cue type, duration and validity, and task. Question-marks (?) indicate an approximate value, when data was unclear or not provided in the original paper to allow calculation of the cueing effect for that condition. Non-significant effects are followed with 'ns'

Robertson \& Kim, 1999; Shomstein \& Behrmann, 2008; Shomstein \& Yantis, 2004; Vecera, 1994).

Real or illusory contours must be present to observe object-based facilitatory effects, and participants need to be aware of their presence (e.g., Ariga et al., 2007). That deep perceptual processing is required fits with the notion that object-based facilitatory effects occur well after figureground segmentation, operating on representations of unique, perceptually complete objects (e.g., Chen, 1998; Moore et al., 1998; see also Chen \& Cave, 2006). This point was cleverly illustrated by Chen and by Moore et al. In Chen's study, object-based facilitation depended on how participants were instructed to perceive the visual display. When participants were biased to perceive a large letter X as being composed of two adjacent Vs, shifts of attention within the cued $\mathrm{V}$ were faster than shifts between the two Vs. However, when the task instructions biased perception of the same display as consisting of a single letter X, object-based facilitation (the difference in RTs between targets appearing on the cued $\mathrm{V}$ versus on the uncued V) was eliminated. Moore, Yantis, and Vaughan (1998; see also Behrmann et al., 1998) showed that object-based facilitatory effects can be observed for partially occluded objects, with no reported difference in the magnitude of the effect from that observed in nonoccluded objects.

Further evidence for the late operation of selective attention across objects-well after the operation of figure-ground and size-scaling processes have occurredcomes from Robertson and Kim (1999). In this study, the perceived length of two physically identical think lines (resembling thin rectangles) influenced the allocation of selective attention, with larger same-object benefits for lines corresponding to the perceived longer corner of an Ames room wall, as compared to the perceived shorter corner of the wall. Since the two lines were really the same length, it would seem that facilitatory effects of attention emerged as a result of consulting a deeply processed representation of the display. In summary, the perceived presence of an object and its attributes, as well as awareness of its presence, can contribute to the observation of reliable facilitatory object-based effects. However, as we will see below, presence alone is not always sufficient. 
Table 4 Summary of IOR cueing effects (in milliseconds) in static object studies. Studies appear in chronological order

\begin{tabular}{|c|c|c|c|c|c|c|c|c|c|}
\hline \multirow[b]{2}{*}{ Experiment } & \multirow[b]{2}{*}{ Objects } & \multicolumn{3}{|c|}{ Duration } & \multirow[b]{2}{*}{ SOA } & \multirow[b]{2}{*}{ MRCTI } & \multicolumn{3}{|c|}{ IOR Effect } \\
\hline & & Cue & Target & Fixation & & & $\begin{array}{c}\text { Cued } \\
\text { Object+ } \\
\text { Location }\end{array}$ & $\begin{array}{c}\text { Cued } \\
\text { Object } \\
\text { Part }\end{array}$ & $\begin{array}{c}\text { Uncued } \\
\text { Object Part }\end{array}$ \\
\hline \multicolumn{10}{|l|}{ Jordan \& Tipper (1999) } \\
\hline \multirow{4}{*}{$\begin{array}{l}E 1, N=36 \\
\text { Trials }=480 \\
\text { (160 per display) }\end{array}$} & & & & & & & & & \\
\hline & Rectangles & 83 & 83 & 83 & 1166 & 583 & 40 & 12 & - \\
\hline & $\begin{array}{c}\text { Kanizsa } \\
\text { Rectangles }\end{array}$ & 83 & 83 & 83 & 1166 & 583 & 45 & 5 ns & - \\
\hline & $\begin{array}{c}\text { Kanizsa } \\
\text { Rectangles } \\
\text { with Contour }\end{array}$ & 83 & 83 & 83 & 1166 & 583 & 39 & 21 & - \\
\hline \multicolumn{10}{|l|}{ Leek, Reppa \& Tipper (2003) } \\
\hline \multirow{7}{*}{$\begin{array}{l}E 1, N=34 \\
\text { Trials=500 } \\
\text { (340 in object present and } \\
160 \text { in object displays) }\end{array}$} & & & & & & & & & \\
\hline & Segmented & 90 & 1500 & 130 & 820 & 430 & 61 & 32 & 44 \\
\hline & L-Shapes & 90 & 1500 & 130 & 1220 & 630 & 56 & 31 & 39 \\
\hline & Unsegmented & 90 & 1500 & 130 & 820 & 430 & 57 & 34 & 38 \\
\hline & L-Shapes & 90 & 1500 & 130 & 1220 & 630 & 52 & 35 & 33 \\
\hline & Obiect Absent & 90 & 1500 & 130 & 820 & 430 & 32 & 13 & 17 \\
\hline & Object Absent & 90 & 1500 & 130 & 1220 & 630 & 25 & 10 & 16 \\
\hline \multicolumn{10}{|l|}{ Reppa \& Leek (2003) } \\
\hline \multirow{3}{*}{$\begin{array}{l}E 1, N=20 \\
\text { Trials }=600\end{array}$} & & 90 & 1500 & 90 & 400 & 180 & 41 & 11 & - \\
\hline & Rectangles & 90 & 1500 & 90 & 820 & 380 & 33 & 10 & - \\
\hline & & 90 & 1500 & 90 & 1220 & 580 & 34 & 12 & - \\
\hline \multirow{4}{*}{$\begin{array}{l}E 2, N=20 \\
\text { Trials }=680 \\
\text { (340 per display) }\end{array}$} & Segmented & 90 & 1500 & 90 & 820 & 380 & 52 & 32 & 43 \\
\hline & L-Shapes & 90 & 1500 & 90 & 1220 & 580 & 32 & 19 & 39 \\
\hline & Unsegmented & 90 & 1500 & 90 & 820 & 380 & 24 & 23 & 26 \\
\hline & L-Shapes & 90 & 1500 & 90 & 1220 & 580 & 39 & 16 & 20 \\
\hline \multicolumn{10}{|l|}{ Reppa \& Leek (2006) } \\
\hline \multirow{6}{*}{$\begin{array}{l}E 1, N=35 \\
\text { Trials }=460 \\
\text { (154 per display) }\end{array}$} & Internally & 90 & 1500 & 130 & 820 & 430 & 49 & 28 & 42 \\
\hline & $\begin{array}{l}\text { Segmented } \\
\text { L-Shapes }\end{array}$ & 90 & 1500 & 130 & 1220 & 630 & 36 & 23 & 37 \\
\hline & Externally & 90 & 1500 & 130 & 820 & 430 & 39 & 35 & 30 \\
\hline & $\begin{array}{l}\text { Segmented } \\
\text { L-Shapes }\end{array}$ & 90 & 1500 & 130 & 1220 & 630 & 28 & 27 & 23 \\
\hline & Unsegmented & 90 & 1500 & 130 & 820 & 430 & 39 & 33 & 31 \\
\hline & Rectangles & 90 & 1500 & 130 & 1220 & 630 & 26 & 25 & 25 \\
\hline
\end{tabular}

Facilitatory effects are influenced by the strength of figure-ground segmentation

Studies using the Egly et al. (1994) two-rectangle paradigm have shown that object-based facilitatory effects are more likely to occur with manipulations that facilitate the construction of perceptual object representations. Object preview time and perceptual complexity are two factors that contribute to obtaining object-based cueing effects.

Object preview time One of the earliest studies relating temporal parameters and the magnitude of object-based effects was reported by Avrahami (1999). She found that object-based facilitatory effects were more likely to arise when the time between the cue and the target was increased, presumably allowing the scene to be segmented into separate perceptual groups or objects, which could then influence attention (but see Lamy \& Egeth, 2002, for the lack of an influence of cue-target interval on facilitatory effects).

The majority of studies investigating temporal parameters have looked at the role of stimulus exposure, or preview time, on the presence and magnitude of objectbased effects by manipulating the observer's exposure to the object stimuli prior to cueing. Table 2 summarises mean facilitatory effects as a function of manipulations of exposure time, and within each study it is clear that increasing the time that the stimulus display is visible directly affects the magnitude of facilitatory cueing effects. These manipulations will now be directly described.

Law and Abrams (2002) reported an elimination of objectbased facilitatory effects by reducing the object preview display duration from 186 to $129 \mathrm{~ms}$. Chen and Cave (2008) later confirmed the influence of preview time as a factor modulating object-based cueing effects. They used a three- 
Table 4 (continued)

\begin{tabular}{|c|c|c|c|c|c|c|c|c|c|}
\hline \multirow[b]{2}{*}{ Experiment } & \multirow[b]{2}{*}{ Objects } & \multicolumn{3}{|c|}{ Duration } & \multirow[b]{2}{*}{ SOA } & \multirow[b]{2}{*}{ MRCTI } & \multicolumn{3}{|c|}{ IOR Effect } \\
\hline & & Cue & Target & Fixation & & & $\begin{array}{l}\text { Cued } \\
\text { Object+ } \\
\text { Location }\end{array}$ & $\begin{array}{l}\text { Cued } \\
\text { Object } \\
\text { Part }\end{array}$ & $\begin{array}{c}\text { Uncued } \\
\text { Object Part }\end{array}$ \\
\hline \multicolumn{10}{|c|}{ List \& Robertson (2006) } \\
\hline $\begin{array}{l}E 1, N=17 \\
\text { Trials }=200\end{array}$ & Rectangles & 82 & 82 & 82 & 1176 & 588 & 36 & 15 & - \\
\hline $\begin{array}{l}E 2, \mathrm{~N}=17 \\
\text { Trials }=400\end{array}$ & Rectangles & 100 & 100 & $\begin{array}{l}100 \\
\text { No }\end{array}$ & $\begin{array}{c}1220 \\
340\end{array}$ & $\begin{array}{l}610 \\
340\end{array}$ & $\begin{array}{l}39 \\
28\end{array}$ & $\begin{array}{c}14 \\
+8 n s\end{array}$ & - \\
\hline $\begin{array}{l}E 3, \mathrm{~N}=17 \\
\text { Trials }=400\end{array}$ & Rectangles & 100 & 100 & $\begin{array}{l}\text { No } \\
\text { No }\end{array}$ & $\begin{array}{c}1220 \\
340\end{array}$ & $\begin{array}{c}1220 \\
340\end{array}$ & $\begin{array}{l}32 ! \\
31 !\end{array}$ & $\begin{array}{l}\text { 4ns } \\
1 \mathrm{~ns}\end{array}$ & - \\
\hline $\begin{array}{l}E 4, \mathrm{~N}=17 \\
\text { Trials }=400\end{array}$ & Rectangles & 112 & 102 & $\begin{array}{l}102 \\
102\end{array}$ & $\begin{array}{c}1253 \\
340\end{array}$ & $\begin{array}{c}1078 \\
165\end{array}$ & $\begin{array}{l}29 \\
36\end{array}$ & $\begin{array}{c}+3 n s \\
4 n s\end{array}$ & - \\
\hline $\begin{array}{l}E 5, N=17 \\
\text { Trials }=400\end{array}$ & Rectangles & 107 & 110 & $\begin{array}{l}107 \\
107\end{array}$ & $\begin{array}{c}1253 \\
340\end{array}$ & $\begin{array}{l}170 \\
170\end{array}$ & $\begin{array}{l}22 \\
44\end{array}$ & $\begin{array}{l}+9 n s \\
+2 n s\end{array}$ & - \\
\hline \multicolumn{10}{|c|}{ Possin, Filoteo, Song \& Salmon (2009) } \\
\hline $\begin{array}{l}\mathrm{E} 1, \mathrm{~N}=18 \\
\text { Trials=384 } \\
\text { (192 per display) }\end{array}$ & $\begin{array}{l}\text { Segmented } \\
\text { L-Shapes }\end{array}$ & 90 & $\begin{array}{c}1000 \text { or } \\
\text { Until } \\
\text { Response }\end{array}$ & $\begin{array}{l}130 \\
130\end{array}$ & $\begin{array}{c}820 \\
1220\end{array}$ & $\begin{array}{l}430 \\
630\end{array}$ & $\begin{array}{l}54 \\
39\end{array}$ & $\begin{array}{l}37 \\
17\end{array}$ & $\begin{array}{l}39 \\
28\end{array}$ \\
\hline & Object Absent & 90 & $\begin{array}{l}1000 \text { or } \\
\text { Until } \\
\text { Response }\end{array}$ & $\begin{array}{l}130 \\
130\end{array}$ & $\begin{array}{c}820 \\
1220\end{array}$ & $\begin{array}{l}430 \\
630\end{array}$ & $\begin{array}{l}42 \\
25\end{array}$ & $\begin{array}{l}31 \\
17\end{array}$ & $\begin{array}{c}22 \\
5\end{array}$ \\
\hline
\end{tabular}

Cueing effects are reported here as a function of object type, cue, target, and fixation cue duration, SOA, and MRCTI. All studies employed a target detection task following an exogenous cue. Dash symbols (-) indicate that the condition was not applicable for that study, and plus symbols $(+)$ indicate facilitatory effects. Question marks (?) denote that the information was unclear or not available, and exclamation marks (!) indicate that the value is an approximate calculation. Non-significant IOR effects are indicated by 'ns'

rectangle display in the formation of a cross to examine whether an endogenous cue would induce object-based benefits for targets appearing on the cued rectangle, as opposed to on one of the smaller, uncued rectangles. They found significant object-based effects when the target was preceded by an object preview time of $1,005 \mathrm{~ms}$. When the object preview time was reduced to $120 \mathrm{~ms}$, there was no longer a significant same-object benefit, leading them to conclude that complete segmentation of the objects from the background played a role in observing object-based benefits.

Object preview time has been shown to interact with target probability in mediating facilitatory cueing effects. In a cued target discrimination task, Shomstein and Behrmann (2008) found that when objects were presented for a mere $200 \mathrm{~ms}$ before the cue-target sequence, RTs were influenced by probability information, with the fastest RTs for targets appearing in high-probability locations, and the slowest for targets appearing in low-probability locations. In contrast, when objects were presented for $1,000 \mathrm{~ms}$ before the cue and target sequence, object-based facilitatory effects were significant regardless of whether the target had a higher probability of appearing on the same or on a different object. That object-based effects were revealed with increased preview time suggests that another level of representation was established and influenced attentional allocation. This is an important finding that demonstrates how subtle manipulations can influence which representation will be active in mediating selective attention and task performance.

Salience of object contours The salience and complexity of object contours in the display can modulate the presence and magnitude of object-based facilitatory effects in twoobject cueing tasks. Contour salience has typically been manipulated by using line contours versus apparent contours (e.g., Moore et al., 1998), by using closed-ended versus open-ended rectangles (e.g., Marino \& Scholl, 2005), by maintaining uniformity of the object's surface (e.g., Hecht \& Vecera, 2007; Watson \& Kramer, 1999), or by colouring two objects differently (e.g., Shomstein \& Behrmann, 2008). Table 3 summarises facilitatory effects as a function of contour manipulations in two-object cueing studies.

Three studies have allowed for direct comparison of the magnitudes of facilitatory object-based effects for objects with different salience (Hecht \& Vecera, 2007; Marino \& Scholl, 2005; Shomstein \& Behrmann, 2008, Exps. 1, 3, and 4). Hecht and Vecera examined the influences of surface uniformity (e.g., uniformity in colour across the contour) and part structure on object-based facilitatory effects (see Table 3 for stimulus examples). In agreement with previous demonstrations of the importance of surface uniformity in object-based attention (e.g., Watson \& 
Kramer, 1999), they found significant object-based facilitatory effects for uniformly coloured (Exps. 1 and 3) but not for nonuniformly coloured (Exp. 2) contours. They further reported that even in the case of nonuniformly coloured contours, if the change in colour coincided with a part boundary (thus adding additional cues to the presence of a single bounded figure), strong and significant object-based effects were reinstated.

Shomstein and Behrmann (2008) presented two differently coloured rectangles, the ends of either of which would be cued followed by a target search display. Despite the low preview time of $200 \mathrm{~ms}$ and a target location probability manipulation, object-based facilitatory effects were significant. Meanwhile, the same preview time of $200 \mathrm{~ms}$ was not sufficient for observing an object-based effect when the two objects were uncoloured outline rectangles. Presumably, the more salient object contours of the coloured rectangles resulted in more easily parsed displays and a greater likelihood that object representations would be created, consulted, and influence spatial cueing.

The data from Shomstein and Behrmann (2008) further demonstrated that object-based effects are capable of overriding high target probabilities (see also Shomstein \& Yantis, 2004). Facilitatory effects can emerge even in the face of probability manipulations at very short object preview times, given strong cues to the presence of unique objects in the display (e.g., when the two contours are differently coloured in the experiment).

Increasing the salience of cues to objecthood may not be guaranteed to influence the strength of object-based effects (e.g., Avrahami, 1999; Marino \& Scholl, 2005). For instance, although closure intuitively seems like it should be an important factor in the generation of object-based representations, it is unlikely to be sufficient to produce object-based effects (e.g., Avrahami, 1999; List \& Robertson, 2007). Explicit closure may also not be necessary, because Marino and Scholl (2005, Exp. 1) found statistically significant, yet equivalent, same-object benefits for openended (5.6-ms benefit) and closed-contour (7.2-ms benefit) rectangles. This null result may reflect the visual system modally completing the open-ended line displays, leading to no functional difference between the two displays. Surface contours do not need to be explicitly closed to be perceived as object parts - for instance, a fold in a blanket. When the result is coupled with the noted lack of power in Marino and Scholl (2005), perceptual salience cannot be discounted as an important factor in producing object-based effects.

The remaining studies shown in Table 3 either did not directly manipulate object salience or simply qualitatively compared their findings with those of previous studies. Nevertheless, it is notable that as objects appear subjectively more salient, facilitatory effects emerge with increasing magnitudes (see the Summary and conclusions section).
Do representations of objects mediate object-based facilitatory effects?

The aforementioned studies suggest that object-based facilitatory effects require sufficient time and cues to figure-ground segmentation to allow distinct object representations to emerge. Furthermore, evidence has shown that object-based facilitatory effects are influenced by perceptually complete representations of objects, either following modal completion (e.g., Moore et al., 1998) or subjective organisation of the contours in the scene (e.g., Chen, 1998). Such evidence suggests that display characteristics such as preview time and the salience of contours can give rise to representations of the display that are qualitatively different from early spatial representations, and that selection can operate within those perceptually complete object representations.

Neuropsychological evidence similarly supports the dissociation between object-based and space-based mechanisms of selection, with each operating on qualitatively different representations. Using the classic Egly et al. (1994) two-rectangle spatial cueing task, de-Wit, Kentridge, and Milner (2009) examined space- and object-based attention in patient DF. Following bilateral lesions in the vicinity of the lateral occipital complex (an area associated with object shape representation and recognition; e.g., Kourtzi \& Kanwisher, 2001; Malach et al., 1995; Martínez et al., 2006), patient DF suffered with severe acquired deficits in object recognition but had preserved figureground segmentation. DF showed normal space-based orienting effects of cue validity, with faster RTs to targets appearing at the same location as, relative to a different location from, the cue. Interestingly, DF showed no objectbased facilitation effects, with RTs to targets appearing on the uncued location of the cued object being no different from those appearing on the uncued object. The lack of object-based facilitatory effects in the presence of intact grouping processes, but with impaired object recognition ability, suggests that selective attention typically operates on object representations that mediate recognition, but was unable to do so in this patient.

So far, evidence has shown that facilitatory cueing effects can be influenced by factors relating to the presence of separate objects in the display. Increasing the amount time objects are viewed and facilitating figure-ground segmentation (e.g., by differentiating objects in the visual array and increasing the salience of object contours) contributes to the generation of object representations (e.g., Rensink \& Enns, 1998; Sekuler \& Palmer, 1992). The aforementioned findings suggest that these same factors can contribute to significant cueing benefits, implicating object representations as influencing selection processes in attention. The following section reveals that a similar pattern of evidence exists for IOR cueing effects. 


\section{Determinants of object-based IOR effects in static displays}

The sensitivity of facilitatory cueing effects to object-based representations is rarely contested. Somewhat more controversial is the influence of objects on the other consequence of exogenous orienting-the IOR effect (e.g., List \& Robertson, 2007; McAuliffe et al., 2001; Schendel et al., 2001). The IOR effect is frequently assumed to reflect the operation of a novelty-seeking mechanism that serves to prevent repeated processing of information at previously attended locations (e.g., Posner \& Cohen, 1984; Posner et al., 1985) and to facilitate the continuous monitoring of the environment for novel visual stimuli (e.g., Klein, 1988, 2000). Implicit in this assumption is that the IOR effect is likely to implicate representations of objects. Indeed, about a decade after its discovery, findings emerged showing object-based IOR effects (e.g., Tipper et al., 1991).

Support for the conclusion that IOR can be object-based comes from four different lines of evidence. First, in moving object displays, IOR for the cued object is significant despite having moved from the cued location (e.g., Ro \& Rafal, 1999; Tipper et al., 1991; Tipper et al., 1999; Tipper et al., 1994). Second, in static object displays, IOR is larger for targets in object-present than in objectabsent displays (e.g., Jordan \& Tipper, 1998; Klein, 1988; Leek et al., 2003; Possin et al., 2009; Takeda \& Yagi, 2000). Third, IOR is modulated by the organisation and salience of object contours in the display (e.g., Jordan \& Tipper, 1999; Leek et al., 2003; Reppa \& Leek, 2003, 2006). Finally, IOR is modulated by an object's internal structure (e.g., Leek et al., 2003, Reppa \& Leek, 2003, 2006; Possin et al., 2009).

The evidence for object-based IOR derived from studies using moving object displays was discussed previously. In the following sections, evidence for the remaining three types of finding supporting an object-based IOR interpretation is reviewed. ${ }^{1}$

IOR effects are influenced by object presence

Object-based IOR effects have been found in tasks using variants of the Egly et al. (1994) two-rectangle paradigm with longer SOAs (e.g., Jordan \& Tipper, 1999; Leek et al., 2003; List \& Robertson, 2007, Exp.1; Reppa \& Leek, 2003, 2006; Possin et al., 2009). Table 4 summarises reported

\footnotetext{
${ }^{1}$ This list of object-based IOR effects does not include effects of longterm IOR (e.g., Tipper, Grison, \& Kessler, 2003). Studies showing long-term IOR effects (up $13 \mathrm{~min}$ ) may examine memory effects that lie well beyond the time course of orienting, as opposed to inhibition of the object's representation during orienting (see Tipper et al., 2003, p. 19).
}

IOR findings based on the two-rectangle paradigm. The first of these studies was reported by Jordan and Tipper (1999), who showed that IOR effects can be associated with the object that the cue appeared on, as opposed to the location of cue alone. Targets appearing at the cued location of the cued object yielded a significant IOR effect, replicating the typical location-based IOR effect. Critically, IOR effects were also significant for targets appearing at uncued locations on cued objects, suggesting that IOR effects are observed across the contours of the cued object in a 2-D plane, and providing another line of evidence that IOR can be object-based. Similarly, Bourke, Partridge, and Pollux (2006) showed that IOR effects can spread across an object in depth. They found that cueing the front surface of a see-through cube yielded significant IOR effects not only for the cued surface but also for an uncued surface of the cube.

Object-based IOR effects are influenced not only by the presence of object contours in the display but by the membership of such contours in a perceptually completed object. Reppa and Leek (2006) showed significant objectbased IOR effects both for unoccluded and for partially occluded objects, with no difference in the magnitude of IOR between the two types of display. This finding illustrates that, as with the facilitatory effects of attention, IOR effects can be influenced by perceptually completed object representations.

IOR is larger in object-present versus object-absent displays

Strong evidence for the notion that IOR can arise from object representations - independently from, and in parallel with, earlier spatial representations - comes from observations of additive location-based and object-based IOR effects in studies using both moving (e.g., Tipper et al., 1999; Tipper et al., 1994) and static (e.g., Jordan \& Tipper, 1998, 1999; but see Theeuwes \& Pratt, 2003) object displays. This dual line of evidence suggests that separate representations of environmental locations and of objects can be elicited by the display and can influence covert orienting independently and in parallel.

In studies using static displays, evidence that objectbased and space-based IOR effects are additive comes from studies showing greater IOR when object contours are present, as opposed to when they are absent from the display (e.g., Klein, 1988; Leek et al., 2003; Possin et al., 2009; Takeda \& Yagi, 2000; but not in McAuliffe et al., 2001, and Weger, Al-Aidroos, \& Pratt, 2008) or when contours do not form an object (e.g., Jordan \& Tipper, 1998). For instance, using a variant of the original Posner cueing paradigm, Jordan and Tipper (1998) first showed that IOR effects significantly increased when boundaries defining distinct objects (physical or apparent) were 
present, as compared to when the boundaries in the scene did not define an object.

The influence of object presence on the magnitude of IOR effects was later demonstrated in studies using a variant of the typical two-rectangle display (e.g., Leek et al., 2003; Possin et al., 2009). Leek, Reppa, and Tipper (2003) presented cues and targets in object-present and object-absent displays randomly mixed within the same block. The targets appeared with equal probability in six different locations on either of two objects (objectpresent condition) or in empty locations (object-absent condition). IOR effects were larger overall in the objectpresent displays than in the object-absent displays (see also Possin et al., 2009). Finally, in Bourke et al.'s (2006) study, the object-based IOR effect observed when two partially overlapping rectangles were linked to form a seethrough cube was double in magnitude as compared to IOR effects when the two rectangles appeared as different objects.

Neuropsychological evidence from Parkinson's disease (PD) patients further supports the hypothesis that spacebased and object-based IOR effects arise from different representations. PD patients have previously been reported to have impaired space-based inhibitory processes (e.g., Filoteo et al., 1997; Hsieh, Lee, Hwang, \& Tsai, 1997; Wright, Burns, Geffen, \& Geffen, 1990), in the presence of intact object-based inhibition (e.g., Possin, Cagigas, Strayer, \& Filoteo, 2006). Unlike previous studies that had separately examined space- and object-based inhibitory processes in different PD patients, Possin, Filoteo, Song, and Salmon (2009) examined both processes in the same patients. They used the task employed by Leek et al. (2003) to examine space- and object-based IOR in PD patients and a group of age-matched healthy controls. Both the healthy control group and the PD patient group showed typical patterns of object-based IOR. However, the PD patients showed an attenuated space-based IOR effect relative to the healthy controls. The reverse pattern of results has been found in older adults, who fail to show object-based IOR in the presence of intact space-based IOR effects (e.g., McAuliffe, Chasteen, \& Pratt, 2006; McCrae \& Abrams, 2001). Such a double dissociation suggests that during the spatial cueing task, multiple representations of the display can emerge, any of which might be consulted, depending on the nature of the attentional network in the individual.

In addition to evidence from spatial cueing studies that IOR effects are influenced by representations of objects, further support comes from "probe-following" studies, where a visual search task is followed by a luminance detection probe task. Probe-following findings support the hypothesis that IOR can be associated with the objects in a scene, as opposed to unoccupied spatial locations (suggested by Tipper et al., 1994, and confirmed in a meta-analysis by Wang \& Klein, 2010).
In the probe-following study by Klein (1988), participants took part in easy or difficult searches and were subsequently asked to detect the presence of a luminance probe (target). The critical manipulation involved the location of the probe, which would appear either at the location that was occupied by a distractor during the search task ("on" probe) or in an unoccupied location ("off" probe). The rationale was that if IOR serves to prevent attention from returning to previously inspected objects, probe detection would then be slower for "on" probes than for "off" probes. The findings confirmed greater IOR for "on" than for "off" probes in the difficult search task. Critically, this difference in IOR magnitude between "on" and "off" probes depended on the maintenance of the visual scene after the search task was completed and during the probe detection task (e.g., Klein \& MacInnes, 1999; Müller \& von Mühlenen, 2000; Takeda \& Yagi, 2000; Wolfe \& Pokorny, 1990; see also the review by Wang \& Klein, 2010). If IOR arises from space-based representations alone, it should have been observed regardless of the disappearance of the objects, as the spatial layout of the environment remained accessible. Apparently, IOR was crucially tied to the maintenance of representations of the scene and of objects within it, because removal of such input obliterated the representations involved, taking the production of IOR effects with it.

IOR is influenced by the salience of object contours

Just as with facilitatory effects, it appears that IOR can be modulated by contour salience, and in particular by contour complexity (e.g., Jordan \& Tipper, 1999; Leek et al., 2003; Reppa \& Leek, 2006). For instance, object-based IOR effects for Kanizsa apparent rectangles in Jordan and Tipper (1999) were small and nonsignificant $(5 \mathrm{~ms})$. However, large and significant IOR effects were observed for outline rectangles $(12 \mathrm{~ms})$, and larger again for outline rectangles that were surrounded by Kanizsa circles (21 ms), a manipulation providing redundant cues to image segmentation. Furthermore, object-based IOR effects were susceptible to practice only for the apparent rectangles (3-ms facilitatory effect in the second block of trials), but not for the Kanizsa-plus-outline rectangles (17 $\mathrm{ms}$ in the second block of trials). Similarly, object-based IOR effects were smaller (11-12 ms; Jordan \& Tipper, 1999; Reppa \& Leek, 2003, Exp. 1) when the objects were outline rectangles, as compared to when the objects were segmented L-shapes (26 ms in Reppa \& Leek, 2003, Exp. 2; and $30 \mathrm{~ms}$ in Leek et al., 2003) or coloured rectangles (29 ms in Reppa \& Leek, 2006). Although the relationship between object contour complexity and magnitude of object-based IOR effects remains to be systematically manipulated and examined in future studies, a survey of Table 4 suggests a trend for larger effects with increasing contour complexity (see the Summary and conclusions section). 
The suggestion that perceptual salience can determine the magnitude of object-based IOR effects is - albeit indirectlysupported by a study by McAuliffe, Pratt, and O'Donnell (2001). They reported a failure to find larger IOR effects from object-present displays. They presented cues and targets on either of two possible locations aligned either horizontally or vertically around a central fixation cross. In half of the trials, each location was surrounded by a closed contour (objectpresent condition), and in the other half of the trials there were no object contours (object-absent condition). In three experiments, they manipulated the SOA from 400 to $1,000 \mathrm{~ms}$ and whether the object-present and object-absent trials were blocked or randomly intermixed. When the object-present and object-absent trials were presented in different blocks, there was no difference in the magnitude of IOR between the two displays. However, significant object-based IOR effects were observed when object-absent and object-present trials were randomly intermixed in the same blocks. The failure to observe object-based IOR in the blocked design might have resulted from the repeated presentation of two task-irrelevant outline squares in the same locations for hundreds of trials, which is likely to have rendered them uninteresting and unnecessary to represent.

IOR is influenced by object-internal structure

Structure-based modulation of IOR, or the SBM effect (e.g., Leek et al., 2003; Possin et al., 2009; Reppa \& Leek, 2003, 2006), provides another line of evidence, highlighting the role of objects as perceptually complete and internally structured entities capable of modulating IOR. The SBM effect refers to the finding that the magnitude of IOR changes depending on the presence of an object-internal contour appearing between the cue and the target. Observations of the SBM effect in studies to date are shown in Table 4.

In the first demonstration of the SBM effect, Reppa and Leek (2003) presented participants with two L-shaped outline stimuli simultaneously on the left and right sides of a central fixation cross (see Table 4). The cue appeared at the centre of one of the L-shapes and was not predictive of the subsequent location of the target. The critical manipulation was whether or not there was a line discontinuity (i.e., a part boundary) between the cue and the target. In the segmented object displays, the target could appear at the cued location, on the cued object part, or on a different part from the cue (uncued part). The key finding, and a hallmark of the SBM effect, was that while significant IOR was found in both the same-part and different-part conditions, IOR was greater in the uncued-part than in the cued-part condition (see Table 4). Later, Possin et al. (2009) replicated the SBM effect in a group of PD patients, who despite impaired space-based IOR showed significant object-based IOR effects. Moreover, in a later study, Reppa and Leek (2006) confirmed that the SBM effect is only triggered by object-internal structural discontinuities, not by discontinuities that are part of an occluding object. Combined, the evidence from healthy adults and PD patients suggests that IOR effects can arise from internally structured representations of objects (Leek, Reppa, \& Arguin, 2005), as opposed merely to global forms.

Are object-based IOR effects in static displays reliable?

Object-based IOR effects have not always been observed in two-object static displays, raising the opportunity to gain a better understanding of the boundary conditions of the effect. In one study, List and Robertson (2007) examined the influence of cue-target SOA and back-to-centre cueing on space-based and object-based IOR effects. In five experiments, space-based IOR was consistently significant, surviving manipulations of SOA and the removal of backto-centre cueing (central fixation brightening after the cue was presented but before the target appeared). In contrast, object-based IOR was observed only when a back-to-centre cue was present and when the most recent cue- (peripheral or central-fixation) to-target interval (MRCTI) was approximately between 600 and $1,200 \mathrm{~ms}$. In the remaining conditions, small and nonsignificant object-based facilitation effects were observed in the presence of significant space-based IOR effects. This led the authors to conclude that object-based effects were fragile and sensitive to backto-centre cueing and to an MRCTI within a very constricted range.

The role that the MRCTI plays in obtaining object-based IOR effects is clearly in need of further examination, given that data reported in the literature violate the conclusions drawn about the range at which object-based effects can be observed (Leek et al., 2003; Reppa \& Leek, 2003, 2006; Possin et al., 2009; as reported in Table 4). Meanwhile, the importance of back-to-centre cueing in observing objectbased IOR effects highlights the need to take into account factors that may influence object perception when looking for object-based effects (see also Ro \& Rafal, 1999). It seems plausible that a back-to-centre cue may have contributed to the maintenance and interpretation of the display as object-based by serving as a reminder of the objects' presence, strengthening the grouping between the target's current location and the previously cued locationand thereby strengthening object-based IOR effects.

While future work is needed to systematically examine the role of the emergence and maintenance of object representations in obtaining robust and reliable objectbased IOR effects - as has started to happen with facilitatory cueing effects - the studies reviewed above suggest that space-based and object-based IOR effects arise from fundamentally different representations of the stimulus 
display and influence the presence and magnitude of the effects. Apart from the numerous instances in which significant object-based IOR has been reported in static displays, the effect has been shown to be modulated by object-internal structure and to operate on perceptually complete representations of objects in the display.

Although object-based IOR effects may be observed under more specific circumstances than space-based effects, it is the contention of the present review that those specific circumstances relate to the generation and maintenance (throughout the experiment) of object representations. Just as location-based IOR effects have been shown to disappear in the presence of cues to an alternative, object-based interpretation of the scene (e.g., Tipper et al., 1999), similarly, object-based IOR effects can disappear when such cues do not exist or are too weak to encourage the construction and maintenance of object representations.

\section{Space-based interpretations of object-based effects}

In response to claims that objects play a role in attentional selection, space-based explanations have emerged attempting to parsimoniously account for all spatial cueing effects using a single, space-based representational medium. The basic tenet is that there is no need to recruit representations of objects in order to explain apparent object-based effects, which can instead be accounted for in terms of selection of space that is "structured by objects" in the display. Two kinds of findings have been presented as evidence that space-based representations can account for object-based effects. These findings are referred to as "objects in space" and "objects with space."

The "objects in space" finding is that, although object representations may be selected, the distance between them in space can still influence cueing effects (e.g., Vecera, 1994; Vecera \& Farah, 1994). This finding was explained using the grouped-locations array representation hypothesis (e.g., Vecera, 1994; Vecera \& Farah, 1994), whereby object-based effects reflect the selection of locations grouped via perceptual grouping processes rather than selection of objects per se (e.g., Ho \& Atchley, 2009; Mozer, 2002; Mozer \& Vecera, 2005; Vecera, 1994; Vecera $\&$ Farah, 1994). Such grouping processes are postulated to operate within a viewer-centred spatial reference frame, resulting in representations of "proto-objects" (e.g., Driver, Davis, Russell, Turatto, \& Freeman, 2001; Rensink, 2000; Rensink \& Enns, 1995) or "grouped arrays of locations" (e.g., Müller \& O'Grady, 2009; O’Grady \& Müller, 2000; Vecera, 1994; Vecera \& Farah, 1994). These representations are still space-based, in the sense that they make the location in space of a group or object explicit and drive selection, while object form and structure are implicit.
Many studies using the Egly et al. (1994) two-object paradigm have reported larger cueing effects for targets appearing on the cued location of the cued object, relative to those appearing on the uncued location of the cued object. This "objects with space" finding suggests that the space within objects is explicitly represented, and it has been suggested that the data may reflect selection not of objects per se, but of perceived space. That is, objects influence cueing effects by structuring space and altering the way it is perceived (e.g., Robertson, 2004; Robertson \& Kim, 1999).

There are several problems with attempting to eliminate object-based representations from explanations of apparent object-based effects. First, irrespective of how much evidence one accrues regarding the adequacy of space-based explanations, one fails to disprove that object-based representations exist and are consulted, or that they have actively played a role in attentional selection within other experiments. All objectbased representations possess contours, which in and of themselves are represented spatially and would presumably have similar properties bounded by the object representation of which they are part. Selection of an object representation need not exclude selection of the space within it (e.g., Hollingworth et al., 2011; Reppa et al., 2010).

A second problem with theoretical approaches that attempt to eliminate object-based explanations in spatial cueing is that, despite their attractiveness on the grounds of parsimony, grouped-array representations and space-based explanations cannot comfortably account for many of the object-based findings recounted in the present review-let alone in the many domains of psychological inquiry outside of spatial cueing, for which object-based explanations seem required. For instance, data showing modulation of facilitatory and IOR spatial cueing effects by contour complexity, distinctiveness, and internal structure, or those showing additive space-based and object-based effects, all seem to implicate object representations that alongside representations of spatial locations are active and can mediate behaviour in parallel. To account for such findings, spacebased accounts will need to make an unprecedented appeal to the notion of the object and its perceptual characteristics, which would presumably make them hard to differentiate from object-based accounts (see Goldsmith, 1998). The task of determining the content and scope of active representations remains important, of course, but spacebased explanations of object-based effects need not negate the role of object representations in mediating spatial cueing effects.

\section{Summary and conclusions}

Spatial cueing has been proven to be an effective tool for elucidating the organisation and structure of representations 
that mediate facilitatory and inhibitory processes resulting from the allocation of selective attention. Clearly, much empirical and theoretical progress has been made over the past 30 years in our understanding of the role that objects and their resulting representations play in the covert orienting of attention. While historically early approaches to spatial cueing assumed and tested space-based representations, later research expanded into questioning whether the representational medium of selective attention might be object-based, either in addition to, or in some cases instead of, simple unstructured spatial representations.

The evidence presented here suggests that both facilitatory and IOR cueing effects, in moving and static object displays, are sensitive to the presence of objects in the display. Cueing effects are observed for perceptually completed objects and are modulated by object salience and structure, suggesting that object representations can be selected and can influence behaviour. Apart from evidence showing that both space- and object-based representations and orienting effects resulting from such representations can occur and influence performance, there is evidence that those representations exist in parallel (e.g., Leek et al., 2003; Reppa \& Leek, 2003; Tipper et al., 1999). What will determine if object representations will be selected and influence orienting effects, as opposed to representations of spatial locations? Emerging from this review of successes and failures in observing object-based facilitatory and inhibitory effects are several practices that clearly play a role in encouraging object-based representations to be created and consulted via visual attention. From this summary of research, it seems that the stronger the cues to object segmentation in the display, the more likely that object representations will be implicated in processing to produce strong and reliable object-based effects.

Some studies have addressed this hypothesis directly by manipulating contour salience, as conveyed by means of object contour uniqueness in the display (e.g., Shomstein \& Behrmann, 2008) or added cues to image segmentation (e.g., Hecht \& Vecera, 2007). Even where such comparisons have not directly been made, findings reported in the literature support the role of object complexity in modulating object-based cueing effects. For instance, looking at Table 3, it appears that the more complex the object stimuli used across studies, the greater the magnitude of objectbased cueing effects that emerged. To examine this more concretely, Fig. 4 plots the magnitude of object-based cueing effects as a function of object complexity for both facilitatory (top row) and inhibitory (bottom row) effects. Complexity is simply quantified in terms of the number of line segments or of the number of vertices in the objects. Even with such simple measures, the outcome is clear: For both facilitatory and IOR object-based effects, increases in object complexity are positively related to increases in the magnitude of object-based cueing effects.
Fig. 4 Mean object-based facilitatory (top row) and IOR (bottom row) effects from Tables 2 and 3 (for facilitatory effects) and Table 4 (for IOR effects), plotted here as a function of (a) the number of line segments and (b) the number of vertices per single object in twoobject displays. $N$ refers to the number of studies per data point
(A)
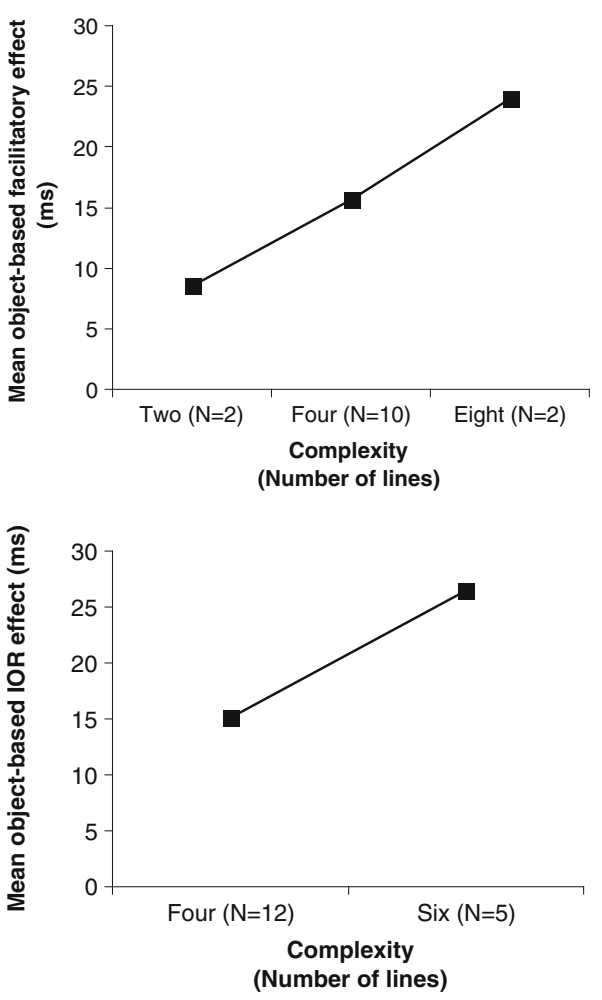

(B)
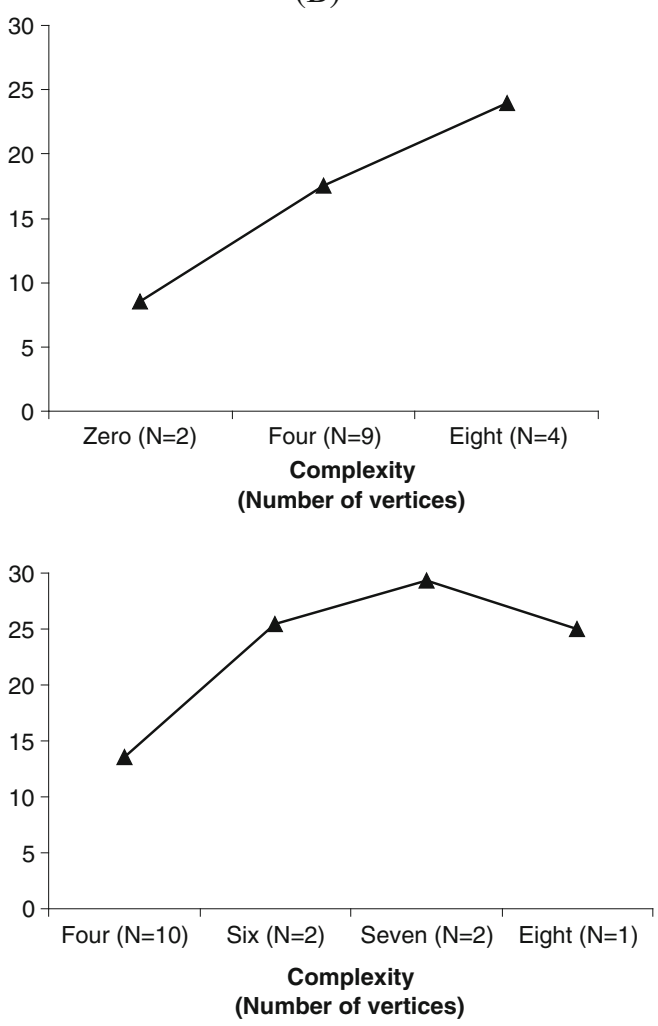
In addition to object complexity, sufficient processing time and the continuing relevance of the objects throughout the subject's task seem necessary prerequisites for object representations to influence performance.

What has been highlighted in the present review is that the notion of objecthood - the factors contributing to its generation, strength, and maintenance of an object file or token - needs to be carefully considered in studies of object-based attention. Instead of rejecting the role that object representations might play in obtaining apparent object-based effects, on the basis of findings that show an absence of such effects, a more fruitful approach may be to examine the factors that contribute to generation and maintenance of object representations in selective attention tasks. As suggested by past reviews of the literature (e.g., Cave \& Bichot, 1999), whether selective attention is mediated by space- or object-based representations need not be an either/or issue. Instead, when an object representation has been constructed and consulted-for instance, when the representation has information in a format from which task performance might benefit - then object-based effects will be observed. However, if cues to objecthood or motivations to consult object-level representations are absent, it would appear that simpler representations mediate performance. Conceptually, this is a significant step towards a grounded understanding of object-based cueing effects and object-based selection.

\section{References}

Abrams, R. A., \& Dobkin, R. S. (1994). Inhibition of return: Effects of attentional cuing on eye movement latencies. Journal of Experimental Psychology: Human Perception and Performance, 20, 467-477. doi:10.1037/0096-1523.20.3.467

Abrams, R. A., \& Law, M. B. (2000). Object-based visual attention with endogenous orienting. Perception \& Psychophysics, 62, 818-833. doi:10.3758/BF03206925

Andersen, G. J. (1990). Focused attention in three-dimensional space. Perception \& Psychophysics, 47, 112-120.

Andersen, G. J., \& Kramer, A. (1993). Limits of focused attention in three-dimensional space. Perception \& Psychophysics, 53, 658667.

Ariga, A., Yokosawa, K., \& Ogawa, H. (2007). Object-based attentional selection and awareness of objects. Visual Cognition, 15, 685-709.

Arnott, S. R., \& Shedden, J. M. (2000). Attention switching in depth using random-dot autostereograms: Attention gradient asymmetries. Perception \& Psychophysics, 62, 1459-1473. doi:10.3758/ BF03212146

Atchley, P., \& Kramer, A. (2001). Object and space-based attentional selection in three-dimensional space. Visual Cognition, 8, 1-32.

Avrahami, J. (1999). Object of attention, objects of perception. Perception \& Psychophysics, 61, 1604-1612. doi:10.3758/BF03213121

Awh, E., Dhaliwal, H., Christensen, S., \& Matsukura, M. (2001). Evidence for two components of object-based selection. Psychological Science, 12, 329-334.
Baylis, G. C., \& Driver, J. (1992). Visual parsing and response competition: The effects of grouping factors. Perception \& Psychophysics, 51, 145-162. doi:10.3758/BF03212239

Behrmann, M., \& Tipper, S. P. (1994). Object-based attentional mechanisms: Evidence from patients with unilateral neglect. In C. Umiltà \& M. Moscovitch (Eds.), Attention and performance $X V$ : Conscious and nonconscious information processing (pp. 351-375). Cambridge: MIT Press, Bradford Books.

Behrmann, M., \& Tipper, S. P. (1999). Attention accesses multiple references frames: Evidence from unilateral neglect. Journal of Experimental Psychology: Human Perception and Performance, $25,83-101$.

Behrmann, M., Zemel, R. S., \& Mozer, M. C. (1998). Object-based attention and occlusion: Evidence from normal participants and a computational model. Journal of Experimental Psychology: Human Perception and Performance, 24, 1011-1036. doi:10.1037/ 0096-1523.24.4.1011

Bennett, P. J., \& Pratt, J. (2001). The spatial distribution of inhibition of return. Psychological Science, 12, 76-80. doi:10.1111/14679280.00313

Berlucchi, G., Tassinari, G., Marzi, C. A., \& di Stefano, M. (1989). Spatial distribution of the inhibitory effects of peripheral noninformative cues on simple reaction time to non-fixated visual targets. Neuropsychologia, 27, 201-221. doi:10.1016/0028-3932 (89)90172-3

Biederman, I. (1987). Recognition-by-components: A theory of human image understanding. Psychological Review, 94, 115147. doi:10.1037/0033-295X.94.2.115

Bourke, P. A., Partridge, H., \& Pollux, P. M. J. (2006). Additive effects of inhibiting attention to objects and locations in threedimensional displays. Visual Cognition, 13, 643-654. doi:10.1080/ 13506280544000309

Brawn, P. T., \& Snowden, R. J. (2000). Attention to overlapping objects: Detection and discrimination of luminance changes. Journal of Experimental Psychology: Human Perception and Performance, 26, 342-358.

Broadbent, D. (1958). Perception and communication. London: Pergamon.

Brown, J. M., \& Denney, H. I. (2007). Shifting attention into and out of objects: Evaluating the processes underlying the object advantage. Perception \& Psychophysics, 69, 606-618.

Cave, K. R., \& Bichot, N. P. (1999). Visuospatial attention: Beyond a spotlight model. Psychonomic Bulletin \& Review, 6, 204-223. doi: $10.3758 / \mathrm{BF} 03212327$

Chen, Z. (1998). Switching attention within and between objects: The role of subjective organization. Canadian Journal of Experimental Psychology, 52, 7-16.

Chen, Z., \& Cave, K. R. (2006). Reinstating object-based attention under positional certainty: The importance of subjective parsing. Perception \& Psychophysics, 68, 992-1003. doi:10.3758/BF03193360

Chen, Z., \& Cave, K. R. (2008). Object-based attention with endogenous cuing and positional certainty. Perception \& Psychophysics, 70, 1435-1443. doi:10.3758/PP.70.8.1435

Christ, S. E., McCrae, C. S., \& Abrams, R. A. (2002). Inhibition of return in static and dynamic displays. Psychonomic Bulletin \& Review, 9, 80-85. doi:10.3758/BF03196258

Conci, M., \& Müller, H. J. (2009). The "beam of darkness": Spreading of the attentional blink within and between objects. Attention, Perception, \& Psychophysics, 71, 1725-1738.

de Gonzaga Gawryszewski, L., Riggio, L., Rizzolatti, G., \& Umiltà, C. (1987). Movements of attention in three spatial dimensions and the meaning of "neutral" cues. Neuropsychologia, 25, 19-29. doi:10.1016/0028-3932(87)90040-6

de-Wit, L. H., Kentridge, R. W., \& Milner, A. D. (2009). Object-based attention and visual area LO. Neuropsychologia, 47, 1483-1490. doi:10.1016/j.neuropsychologia.2008.11.002 
Downing, C., \& Pinker, S. (1985). The spatial structure of visual attention. In M. I. Posner \& O. S. M. Marin (Eds.), Attention and performance XI (pp. 171-187). Hillsdale: Erlbaum.

Driver, J., Davis, G., Russell, C., Turatto, M., \& Freeman, E. (2001). Segmentation, attention and phenomenal objects. Cognition, 80, $61-95$.

Duncan, J. (1984). Selective attention and the organization of visual information. Journal of Experimental Psychology. General, 113, 501-517. doi:10.1037/0096-3445.113.4.501

Egly, R., Driver, J., \& Rafal, R. D. (1994). Shifting visual attention between objects and locations: Evidence from normal and parietal lesion subjects. Journal of Experimental Psychology. General, 123, 161-177. doi:10.1037/0096-3445. 123.2.161

Egly, R., \& Homa, D. (1991). Reallocation of visual attention. Journal of Experimental Psychology: Human Perception and Performance, 17, 142-159.

Enns, J. T., \& Rensink, R. A. (1990). Sensitivity to three-dimensional orientation in visual search. Psychological Science, 1, 323-326. doi:10.1111/j.1467-9280.1990.tb00227.x

Eriksen, B. A., \& Eriksen, C. W. (1974). Effects of noise letters upon the identification of a target letter in a nonsearch task. Perception \& Psychophysics, 16, 143-149. doi:10.3758/BF03203267

Eriksen, C. W., \& Hoffman, J. (1972). Temporal and spatial characteristics of selective encoding from visual displays. Perception \& Psychophysics, 12, 201-204.

Eriksen, C. W., \& St James, J. D. (1986). Visual attention within and around the field of focal attention: A zoom lens model. Perception \& Psychophysics, 40, 225-240. doi:10.3758/ BF03211502

Eriksen, C. W., \& Yeh, Y. (1985). Allocation of attention in the visual field. Journal of Experimental Psychology: Human Perception and Performance, 11, 583-597. doi:10.1037/0096-1523. 11.5.583

Filoteo, J. V., Delis, D. C., Salmon, D. P., Demadura, T., Roman, M. J., \& Shults, C. W. (1997). An examination of the nature of attentional deficits in patients with Parkinson's disease: Evidence from a spatial orienting task. Journal of the International Neuropsychological Society, 3, 337-347.

Gibson, B. S., \& Egeth, H. (1994). Inhibition of return to object-based and environment-based locations. Perception \& Psychophysics, 55, 323-339. doi:10.3758/BF03207603

Goldsmith, M. (1998). What's in a location? Comparing object-based and space-based models of feature integration in visual search. Journal of Experimental Psychology. General, 127, 189-219. doi:10.1037/0096-3445.127.2.189

Goldsmith, M., \& Yeari, M. (2003). Modulation of object-based attention by spatial focus under endogenous and exogenous orienting. Journal of Experimental Psychology: Human Perception and Performance, 29, 897-918.

Grossberg, S., Mingolla, E., \& Ross, W. D. (1994). A neural theory of attentive visual search: Interactions of boundary, surface, spatial, and object representations. Psychological Review, 101, 470-489. doi:10.1037/0033-295X.101.3.470

Haimson, C., \& Behrmann, M. (2001). Cued visual attention does not distinguish between occluded and occluding objects. Psychonomic Bulletin \& Review, 8, 496-503.

Han, S., Wan, X., Wang, T., \& Humphreys, G. W. (2005). Shifts of spatial attention in perceived 3-D space. Quarterly Journal of Experimental Psychology, 58A, 753-764.

He, Z., \& Nakayama, K. (1995). Visual attention to surfaces in threedimensional space. Proceedings of the National Academy of Sciences, 92, 11155-11159.

Hecht, L. N., \& Vecera, S. P. (2007). Attentional selection of complex objects: Joint effects of surface uniformity and part structure. Psychonomic Bulletin \& Review, 14, 1205-1211. doi:10.3758/ BF03193114
Ho, M. C., \& Atchley, P. (2009). Perceptual load modulates objectbased attention. Journal of Experimental Psychology: Human Perception and Performance, 35, 1661-1669.

Hollingworth, A., Maxcey-Richard, A. M., Vecera, S. P. (2011). The spatial distribution of attention within and across objects. Journal of Experimental Psychology: Human Perception and Performance. doi: $10.1037 / \mathrm{a} 0024463$

Houghton, G., \& Tipper, S. P. (1994). A model of inhibitory mechanisms in selective attention. In D. Dagenbach \& T. H. Carr (Eds.), Inhibitory processes in attention, memory, and language (pp. 53-112). San Diego: Academic.

Hsieh, S., Lee, C. Y., Hwang, W. J., \& Tsai, J. J. (1997). Object-based and location-based shifting of attention in Parkinson's disease. Perceptual and Motor Skills, 85, 1315-1325.

Humphreys, G. W., \& Riddoch, M. J. (1994). Attention to withinobject and between-object spatial representations: Multiple sites for visual selection. Cognitive Neuropsychology, 11, 207-241. doi:10.1080/02643299408251974

Humphreys, G. W., \& Riddoch, M. J. (1995). Separate coding of space within and between perceptual objects: Evidence from unilateral visual neglect. Cognitive Neuropsychology, 12, 283311. doi:10.1080/02643299508252000

Iani, C., Nicoletti, R., Rubichi, S., \& Umiltà, C. (2001). Shifting attention between objects. Cognitive Brain Research, 11, 157-164.

Jordan, H., \& Tipper, S. P. (1998). Object-based inhibition of return in static displays. Psychonomic Bulletin \& Review, 5, 504-509.

Jordan, H., \& Tipper, S. P. (1999). Spread of inhibition across an object's surface. British Journal of Psychology, 90, 495-507.

Kahneman, D., Treisman, A., \& Gibbs, B. J. (1992). The reviewing of object files: Object-specific integration of information. Cognitive Psychology, 24, 175-219. doi:10.1016/0010-0285(92)90007-O

Kingstone, A., \& Pratt, J. (1999). Inhibition of return is composed of attentional and oculomotor processes. Perception \& Psychophysics, 61, 1046-1054. doi:10.3758/BF03207612

Klein, R. (1988). Inhibitory tagging system facilitates visual search. Nature, 334, 430-431. doi:10.1038/334430a0

Klein, R. M. (2000). Inhibition of return. Trends in Cognitive Sciences, 4, 138-147. doi:10.1016/S1364-6613(00)01452-2

Klein, R. M., Christie, J., \& Morris, E. (2005). Vector averaging of inhibition of return. Psychonomic Bulletin \& Review, 12, 295-300.

Klein, R. M., \& MacInnes, W. J. (1999). Inhibition of return is a foraging facilitator in visual search. Psychological Science, 10, 346-352. doi:10.1111/1467-9280.00166

Kourtzi, Z., \& Kanwisher, N. (2001). Representation of perceived object shape by the human lateral occipital complex. Science, 293, 1506-1509. doi:10.1126/science.1061133

Kramer, A. F., \& Jacobson, A. (1991). Perceptual organization and focused attention: The role of objects and proximity in visual processing. Perception \& Psychophysics, 50, 267-284.

Kramer, A. F., Webber, T. A. \& Watson, S. E. (1997). Object-based attentional selection -grouped arrays or spatially invariant representations?: Comment on Vecera and Farah (1994). Journal of Experimental Psychology: General, 126, 3-13.

Kravitz, D. J., \& Behrmann, M. (2008). The space of an object: Object attention alters the spatial gradient in the surround. Journal of Experimental Psychology: Human Perception and Performance, 34, 298-309.

Kwak, H. W., \& Egeth, H. E. (1992). Consequences of allocating attention to locations and to other attributes. Perception \& Psychophysics, 51, 455-464.

LaBerge, D. (1983). Spatial extent of attention to letters and words. Journal of Experimental Psychology: Human Perception and Performance, 9, 371-379. doi:10.1037/0096-1523.9.3.371

LaBerge, D., \& Brown, V. (1989). Theory of attentional operations in shape identification. Psychological Review, 96, 101-124. doi:10.1037/0033-295X.96.1.101 
Lamy, D., \& Egeth, H. (2002). Object-based selection: The role of attentional shifts. Perception \& Psychophysics, 64, 52-66.

Lamy, D., \& Tsal, Y. (2000). Object features, object locations, and object files: Which does selective attention activate and when? Journal of Experimental Psychology: Human Perception and Performance, 26, 1387-1400. doi:10.1037/0096-1523.26.4.1387

Lavie, N., \& Driver, J. (1996). On the spatial extent of attention in object-based visual selection. Perception \& Psychophysics, 58, 1238-1251. doi:10.3758/BF03207556

Law, M. B., \& Abrams, R. A. (2002). Object-based selection within and beyond the focus of spatial attention. Perception \& Psychophysics, 64, 1017-1027.

Leek, E. C., Reppa, I., \& Arguin, M. (2005). The structure of 3D object shape representations: Evidence from whole-part matching. Journal of Experimental Psychology: Human Perception and Performance, 31, 668-684.

Leek, E. C., Reppa, I., \& Tipper, S. P. (2003). Inhibition of return for objects and locations in static displays. Perception \& Psychophysics, 65, 388-395.

List, A., \& Robertson, L. C. (2007). Inhibition of return and objectbased attentional selection. Journal of Experimental Psychology: Human Perception and Performance, 33, 1322-1334.

Macquistan, A. D. (1997). Object-based allocation of visual attention in response to exogenous, but not endogenous, spatial precues. Psychonomic Bulletin \& Review, 4, 512-515.

Malach, R., Reppas, J. B., Benson, R. R., Kwong, K. K., Jiang, H., Kennedy, W. A., et al. (1995). Object-related activity revealed by functional magnetic resonance imaging in human occipital cortex. Proceedings of the National Academy of Sciences, 92, 8135-8139.

Mari-Beffa, P., Houghton, G., Estevez, A. F., \& Fuentes, L. J. (2000). Word-based grouping affects the prime-task effect on semantic priming. Journal of Experimental Psychology: Human Perception and Performance, 26, 469-479.

Marino, A. C., \& Scholl, B. J. (2005). The role of closure in defining the "objects" of object-based attention. Perception \& Psychophysics, 67, 1140-1149.

Marr, D. (1982). Vision. San Francisco: W.H. Freeman.

Marrara, M. T., \& Moore, C. M. (2003). Object-based selection in the two-rectangles method is not an artefact of the three-sided directional cue. Perception \& Psychophysics, 65, 1103-1109.

Martínez, A., Teder-Sälejärvi, W., Vazquez, M., Molholm, S., Foxe, J. J., Javitt, D. C., et al. (2006). Objects are highlighted by spatial attention. Journal of Cognitive Neuroscience, 18, 298-310. doi:10.1162/089892906775783642

Maylor, E. A. (1985). Facilitatory and inhibitory components of orienting in visual space. In M. I. Posner \& O. S. M. Marin (Eds.), Attention and performance XI (pp. 189-204). Hillsdale: Erlbaum.

Maylor, E. A., \& Hockey, R. (1985). Inhibitory component of externally controlled covert orienting in visual space. Journal of Experimental Psychology: Human Perception and Performance, 11, 777-787. doi:10.1037/0096-1523.11.6.777

McAuliffe, J., Chasteen, A. L., \& Pratt, J. (2006). Object- and location-based inhibition of return in younger and older adults. Psychology and Aging, 21, 406-410.

McAuliffe, J., Pratt, J., \& O’Donnell, C. (2001). Examining locationbased and object-based components of inhibition in static displays. Perception \& Psychophysics, 63, 1072-1082.

McCrae, C. S., \& Abrams, R. A. (2001). Age-related differences in objectand location-based inhibition of return of attention. Psychology and Aging, 16, 437-449. doi:10.1037/0882-7974.16.3.437

Mevorach, C., Humphreys, G. W., \& Shalev, L. (2006). Opposite biases in salience-based selection for the left and right posterior parietal cortex. Nature Neuroscience, 9, 740-742.

Moore, C. M., Yantis, S., \& Vaughan, B. (1998). Object-based visual selection: Evidence from perceptual completion. Psychological Science, 9, 104-110. doi:10.1111/1467-9280.00019
Moran, J., \& Desimone, R. (1985). Selective attention gates visual processing in the extrastriate cortex. Science, 229, 782-784. doi: $10.1126 /$ science. 4023713

Mozer, M. C. (2002). Frames of reference in unilateral neglect and visual perception: A computational perspective. Psychological Review, 109, 156-185.

Mozer, M. C., \& Vecera, S. P. (2005). Object- and space-based attention. In L. Itti, G. Rees, \& J. Tsotsos (Eds.), Neurobiology of attention (pp. 130-134). New York: Elsevier.

Müller, H. J., \& O'Grady, R. B. (2009). Object-based selection operating on a spatial representation made salient by dimensional segmentation mechanisms: A re-investigation of Egly and Homa (1984). Psychological Research, 73, 271-286.

Müller, H. J., \& von Mühlenen, A. (1996). Attentional tracking and inhibition of return in dynamic displays. Perception \& Psychophysics, 58, 224-249.

Müller, H. J., \& von Mühlenen, A. (2000). Probing distractor inhibition in visual search: Inhibition of return. Journal of Experimental Psychology: Human Perception and Performance, 26, 1591-1605. doi:10.1037/0096-1523.26.5.1591

Müller, N. G., \& Kleinschmidt, A. (2003). Dynamic interaction of object- and space-based attention in retinotopic visual areas. Journal of Neuroscience, 23, 9812-9816.

O'Grady, R. B., \& Müller, H. J. (2000). Object-based selection operates on a grouped array of locations. Perception \& Psychophysics, 62, 1655-1667.

Posner, M. I. (1980). Orienting of attention. Quarterly Journal of Experimental Psychology, 32, 3-25. doi:10.1080/003355580 08248231

Posner, M. I., \& Cohen, Y. (1984). Components of visual orienting. In H. Bouma \& D. G. Bouwhuis (Eds.), Attention and performance $X$ : Control of language processes (pp. 531-556). Hillsdale: Erlbaum.

Posner, M. I., Rafal, R. D., Choate, L. S., \& Vaughan, J. (1985). Inhibition of return: Neural basis and function. Cognitive Neuropsychology, 2, 211-228. doi:10.1080/02643298508252866

Posner, M. I., Snyder, C. R., \& Davidson, B. J. (1980). Attention and the detection of signals. Journal of Experimental Psychology. General, 109, 160-174. doi:10.1037/0096-3445. 109.2.160

Possin, K. L., Cagigas, X. E., Strayer, D. L., \& Filoteo, J. V. (2006). Lack of impairment in patients with Parkinson's disease on an object-based negative priming task. Perceptual and Motor Skills, 102, 219-230.

Possin, K. L., Filoteo, J. V., Song, D. D., \& Salmon, D. P. (2009). Space-based but not object-based inhibition of return is impaired in Parkinson's disease. Neuropsychologia, 47, 1694-1700.

Pratt, J., \& McAuliffe, J. (1999). Examining the effects of practice on inhibition of return in static displays. Perception \& Psychophysics, 61, 756-765.

Pratt, J., \& Sekuler, A. B. (2001). The effects of occlusion and past experience on the allocation of object-based attention. Psychonomic Bulletin \& Review, 8, 721-727.

Pylyshyn, Z. W. (2001). Visual indexes, preconceptual objects, and situated vision. Cognition, 80, 127-158. doi:10.1016/S00100277(00)00156-6

Rensink, R. A. (2000). Seeing, sensing, and scrutinizing. Vision Research, 40, 1469-1487.

Rensink, R. A., \& Enns, J. T. (1995). Preemption effects in visual search: Evidence for low-level grouping. Psychological Review, 102, 101-130. doi:10.1037/0033-295X.102.1.101

Rensink, R. A., \& Enns, J. T. (1998). Early completion of occluded objects. Vision Research, 38, 2489-2505.

Reppa, I., Fougnie, D., \& Schmidt, W. C. (2010). How does attention spread across objects oriented in depth? Attention, Perception, \& Psychophysics, 72, 912-925. doi:10.3758/APP.72.4.912 
Reppa, I., \& Leek, E. C. (2003). The modulation of inhibition of return by object-internal structure: Implications for theories of object-based attentional selection. Psychonomic Bulletin \& Review, 10, 493-502. doi:10.3758/BF03196512

Reppa, I., \& Leek, E. C. (2006). Structure-based modulation of inhibition of return is triggered by object-internal but not occluding shape features. Quarterly Journal of Experimental Psychology, 59, 1857-1866. doi:10.1080/17470210600872113

Reuter-Lorenz, P., Drain, M., \& Hardy-Morais, C. (1996). Objectcentered attentional biases in the normal brain. Journal of Cognitive Neuroscience, 8, 540-550.

Richard, A., Lee, H., \& Vecera, S. P. (2008). Attentional spreading in object-based attention. Journal of Experimental Psychology: Human Perception and Performance, 34, 842-853.

Ro, T., \& Rafal, R. D. (1999). Components of reflexive visual orienting to moving objects. Perception \& Psychophysics, 61, 826-836.

Robertson, L. C. (2004). Space, objects, minds and brains. New York: Psychology.

Robertson, L. C., \& Kim, M.-S. (1999). Effects of perceived space on spatial attention. Psychological Science, 10, 76-79. doi:10.1111/ $1467-9280.00110$

Samuel, A. G., \& Kat, D. (2003). Inhibition of return: A graphical meta-analysis of its time course and an empirical test of its temporal and spatial properties. Psychonomic Bulletin \& Review, 10, 897-906

Schendel, K. L., Robertson, L. C., \& Treisman, A. (2001). Objects and their locations in exogenous cuing. Perception \& Psychophysics, 63, 577-594. doi:10.3758/BF03194423

Scholl, B. J. (2001). Objects and attention: The state of the art. Cognition, 80, 1-46. doi:10.1016/S0010-0277(00)00152-9

Scholl, B. J., Pylyshyn, Z. W., \& Feldman, J. (2001). What is a visual object? Evidence from target merging in multiple object tracking. Cognition, 80, 159-177. doi:10.1016/S0010-0277(00)00157-8

Sekuler, A. B., \& Palmer, S. E. (1992). Perception of partly occluded objects: A microgenetic analysis. Journal of Experimental Psychology. General, 121, 95-111. doi:10.1037/0096-3445.121.1.95

Shomstein, S., \& Behrmann, M. (2008). Object-based attention: Strength of object representation and attentional guidance. Perception \& Psychophysics, 70, 132-144. doi:10.3758/ PP.70.1.132

Shomstein, S., \& Yantis, S. (2004). Configural and contextual prioritization in object-based attention. Psychonomic Bulletin \& Review, 11, 247-253. doi:10.3758/BF03196566

Shulman, G. L., Remington, R. W., \& McLean, J. P. (1979). Moving attention through visual space. Journal of Experimental Psychology: Human Perception and Performance, 5, 522-526.

Snyder, J. J., Schmidt, W. C., \& Kingstone, A. (2001). Attentional momentum does not underlie the inhibition of return effect. Journal of Experimental Psychology: Human Perception and Performance, 27, 1420-1432. doi:10.1037/0096-1523.27. 6.1420

Soto, D., \& Blanco, M. J. (2004). Spatial attention and object-based attention: A comparison within a single task. Vision Research, 44, 69-81.

Takeda, Y., \& Yagi, A. (2000). Inhibitory tagging in visual search can be found if search stimuli remain visible. Perception \& Psychophysics, 62, 927-934. doi:10.3758/BF03212078

Tanaka, Y., \& Shimojo, S. (1996). Location versus feature: Reaction time reveals dissociation between two visual functions. Vision Research, 36, 2125-2140.

Tassinari, G., Aglioti, S., Chelazzi, L., Peru, A., \& Berlucchi, G. (1994). Do peripheral non-informative cues induce early facilitation of target detection? Vision Research, 34, 179-189. doi:10.1016/0042-6989(94)90330-1
Tassinari, G., \& Berlucchi, G. (1993). Sensory and attentional components of slowing of manual reaction time to non-fixated visual targets by ipsilateral primes. Vision Research, 33, 1525-1534.

Taylor, T. L., \& Klein, R. M. (2000). Visual and motor effects in inhibition of return. Journal of Experimental Psychology: Human Perception and Performance, 26, 1639-1656. doi:10.1037/00961523.26.5.1639

Theeuwes, J., Mathôt, S., \& Kingstone, A. (2010). Object-based eye movements: The eyes prefer to stay within the same object. Attention, Perception, \& Psychophysics, 72, 597-601. doi:10.3758/APP.72.3.597

Theeuwes, J., \& Pratt, J. (2003). Inhibition of return spreads across 3-D space. Psychonomic Bulletin \& Review, 10, 616-620.

Tipper, S. P., \& Behrmann, M. (1996). Object-centered not scenebased visual neglect. Journal of Experimental Psychology: Human Perception and Performance, 22, 1261-1278.

Tipper, S. P., Brehaut, J. C., \& Driver, J. (1990). Selection of moving and static objects for the control of spatially directed action. Journal of Experimental Psychology: Human Perception and Performance, 16, 492-504. doi:10.1037/0096-1523.16.3.492

Tipper, S. P., Driver, J., \& Weaver, B. (1991). Object-centred inhibition of return of visual attention. Quarterly Journal of Experimental Psychology, 43A, 289-298. doi:10.1080/14640749108400971

Tipper, S. P., Grison, S., \& Kessler, K. (2003). Long-term inhibition of return of attention. Psychological Science, 14, 19-25.

Tipper, S. P., Jordan, H., \& Weaver, B. (1999). Scene-based and object-centered inhibition of return: Evidence for dual orienting mechanisms. Perception \& Psychophysics, 61, 50-60.

Tipper, S. P., Weaver, B., Jerreat, L. M., \& Burak, A. L. (1994). Objectbased and environment-based inhibition of return of visual attention. Journal of Experimental Psychology: Human Perception and Performance, 20, 478-499. doi:10.1037/0096-1523.20.3.478

Tipper, S. P., Weaver, B., Rafal, R., Starrveldt, Y., Ro, T., Egly, R., et al. (1997). Object-based facilitation and inhibition from visual orienting in the human split-brain. Journal of Experimental Psychology: Human Perception and Performance, 23, 15221532. doi:10.1037/0096-1523.23.5.1522

Treisman, A. (1982). Perceptual grouping and attention in visual search for features and for objects. Journal of Experimental Psychology: Human Perception and Performance, 8, 194-214.

Tsal, Y. (1983). Movements of attention across the visual field. Journal of Experimental Psychology: Human Perception and Performance, 9, 523-530.

Ullman, S. (1989). Aligning pictorial descriptions: An approach to object recognition. Cognition, 32, 193-254.

Umiltà, C., Castiello, U., Fontana, M., \& Vestri, A. (1995). Objectcentred orienting of attention. Visual Cognition, 2, 165-181. doi:10.1080/13506289508401729

Vecera, S. P. (1994). Grouped locations and object-based attention: Comment on Egly, Driver, and Rafal (1994). Journal of Experimental Psychology. General, 123, 316-320. doi:10.1037/ 0096-3445.123.3.316

Vecera, S. P., Behrmann, M., \& Filapek, J. (2001). Attending to the parts of a single object: Part-based selection limitations. Perception \& Psychophysics, 63, 308-321. doi:10.3758/BF03194471

Vecera, S. P., Behrmann, M., \& McGoldrick, J. (2000). Selective attention to the parts of an object. Psychonomic Bulletin \& Review, 7, 301-308. doi:10.3758/BF03212985

Vecera, S. P., \& Farah, M. J. (1994). Does visual attention select objects or locations? Journal of Experimental Psychology. General, 123, 146-160. doi:10.1037/0096-3445.123.2.146

Vivas, A. B., Humphreys, G. W., \& Fuentes, L. J. (2008). Objectbased inhibition of return in patients with posterior parietal damage. Neuropsychology, 22, 169-176. 
Wang, Z., \& Klein, R. M. (2010). Searching for inhibition of return in visual search: A review. Vision Research, 50, 220-228. doi:10.1016/ j.visres.2009.11.013

Watson, D. G., \& Humphreys, G. W. (1998). Visual marking of moving objects: A role for top-down feature-based inhibition in selection. Journal of Experimental Psychology: Human Perception and Performance, 24, 946-962.

Watson, S. E., \& Kramer, A. F. (1999). Object-based visual selective attention and perceptual organization. Perception \& Psychophysics, 61, 31-49. doi:10.3758/BF03211947

Weaver, B., Lupiáñez, J., \& Watson, F. L. (1998). The effects of practice on object-based, location-based, and static-display inhibition of return. Perception \& Psychophysics, 60, 9931003. doi:10.3758/BF03211934
Weger, U. W., Al-Aidroos, N., \& Pratt, J. (2008). Objects do not aid inhibition of return in crossing the vertical meridian. Psychological Research, 72, 176-182.

Wolfe, J. M., \& Bennett, S. C. (1997). Preattentive object files: Shapeless bundles of basic features. Vision Research, 37, 25-43. doi:10.1016/S0042-6989(96)00111-3

Wolfe, J. M., \& Pokorny, C. W. (1990). Inhibitory tagging in visual search: A failure to replicate. Perception \& Psychophysics, 48, 357-362. doi:10.3758/BF03206686

Wright, M. J., Burns, R. J., Geffen, G. M., \& Geffen, L. B. (1990). Covert orientation of visual attention in Parkinson's disease: An impairment in the maintenance of attention. Neuropsychologia, 28, 151-159.

Zimba, L. D., \& Hughes, H. C. (1987). Distractor-target interactions during directed visual attention. Spatial Vision, 2, 117-149. 